\title{
Sustaining Optimal Motivation: A Longitudinal Analysis of Interventions to Broaden Participation of Underrepresented Students in STEM
}

\author{
Paul R. Hernandez, \\ School of Education, Colorado State University \\ P. Wesley Schultz, \\ Department of Psychology, California State University San Marcos \\ Mica Estrada, \\ Department of Psychology, California State University San Marcos \\ Anna Woodcock, and \\ Department of Psychological Sciences, Purdue University \\ Randie C. Chance \\ Department of Psychology, Southern Illinois University Carbondale \\ Paul R. Hernandez: paul.hernandez@colostate.edu
}

\begin{abstract}
The underrepresentation of racial minorities and women in science, technology, engineering, and mathematics (STEM) disciplines is a national concern. Goal theory provides a useful framework from which to understand issues of underrepresentation. We followed a large sample of highachieving African American and Latino undergraduates in STEM disciplines attending 38 institutions of higher education in the United States over 3 academic years. We report on the science-related environmental factors and person factors that influence the longitudinal regulation of goal orientations. Further, we examine how goal orientations in turn influence distal academic outcomes such as performance and persistence in STEM. Using SEM-based parallel process latent growth curve modeling, we found that (a) engagement in undergraduate research was the only factor that buffered underrepresented students against an increase in performance-avoidance goals over time; (b) growth in scientific self-identity exhibited a strong positive effect on growth in task and performance-approach goals over time; (c) only task goals positively influenced students' cumulative grade point average, over and above baseline grade point average; and (d) performance-avoidance goals predicted student attrition from the STEM pipeline. We discuss the implications of these findings for underrepresented students in STEM disciplines.
\end{abstract}

\section{Keywords}

minority groups; STEM; academic achievement; goal orientation; longitudinal studies

Goal theory has been widely used to understand why individuals strive to achieve, particularly in academic contexts. Consider the tale of three strikingly familiar 
undergraduates engaged in a research methods class: Mark, Sam, and Esmerelda (Barron \& Harackiewicz, 2001a). Mark showed little interest beyond what was covered on tests and received a high grade in the class. Sam was highly engaged in class activities and in deeper discussions of the material but earned only a $\mathrm{C}$ in the class because he focused on personal interests rather than grades. Esmerelda exhibited deep engagement with the material and focused on what would becovered on the tests, and as a consequence, she performed well in the class. As Barron and Harackiewicz (2001a) noted, both Mark and Sam were only partially successful in the class. Mark achieved the highest grade in the class but cultivated only a surface-level interest in the material, and Sam developed a deep interest in the subject but performed relatively poorly. According to Barron and Harackiewicz (2001a), Esmerelda is the most likely student to experience long-term educational achievement in science because only she exhibited optimal motivation for success in a complex and often competitive environment. However, the picture of Esmerelda as someone who desires to develop scientific expertise and perform well is only one snapshot in time. Esmerelda exhibited optimal motivation during that semester in that course, but will she maintain her high levels of motivation to become a scientist as her classes, her peers, and her professors change?

A large body of research has examined how goal orientations in a particular classroom environment relate to patterns of cognitive engagement and achievement in that context (Payne, Youngcourt, \& Beaubien, 2007). However, relatively little research has focused on the factors that sustain or encourage optimal motivation in goal orientations across contexts over long periods of time, particularly among racially diverse populations or among college students pursuing science, technology, engineering, or mathematics (STEM) degrees (E. M. Anderman \& Young, 1994; Fryer \& Elliot, 2007; Pintrich, 1999). These gaps in the literature are particularly important as there is a national recognition of the need to understand the factors that sustain motivation to pursue STEM careers, particularly among underrepresented groups in the STEM disciplines (Byars-Winston, Estrada, Howard, Davis, \& Zalapa, 2010; Cook \& Córdova, 2007).

\section{Underrepresented Students in STEM}

Attracting and retaining women and underrepresented minorities in STEM disciplines is a national priority; however, trends for their persistence are relatively bleak. The number of African American and Latino students choosing scientific or engineering branches of the educational pipeline or pursuing careers in STEM disciplines, is particularly small relative to that of their White and Asian counterparts (Berryman, 1983; Snyder \& Hoffman, 2001; Snyder \& Tan, 2006). Minority students, particularly African Americans and Latinos, are less likely to complete either undergraduate or advanced degrees than are their White and Asian counterparts (Cook \& Córdova, 2007; Koenig, 2009; Myers \& Pavel, 2011). The failure to retain minorities and women in STEM has been described as leaks in the scientific pipeline.

\section{Fixing the "Leaky" Pipeline}

Numerous publicly and privately funded studies have examined the factors that cause such leaks with a particular focus on how to sustain motivation and interest in the sciences among underrepresented students (Alper, 1993). Publicly and privately funded minority training programs have emerged as a key intervention to broaden participation in the STEM disciplines, and most programs include combinations of research experience and mentorship (Alper, 1993; Collea, 1990).

In general, cross-sectional and longitudinal evaluations of these programs indicate that they are successful in supporting underrepresented students' interest and pursuit of STEM 
degrees and careers (Estrada, Woodcock, Hernandez, \& Schultz, 2011; Maton \& Hrabowski, 2004; Maton, Sto Domingo, Stolle-McAllister, Zimmerman, \& Hrabowski, 2009; Myers \& Pavel, 2011; Pender, Marcotte, Sto Domingo, \& Maton, 2010; Schultz et al., 2011).

Research has found that mentoring has a positive effect on sustaining interest in the sciences (Haring, 1999; Pfund, Pribbenow, Branchaw, Lauffer, \& Handelsman, 2006). Similarly, taking part in research activities (e.g., coursework, participation in a faculty member's lab, or a summer workshop) has positive effects on sustained interest in the sciences and learning (Carter, Mandell, \& Maton, 2009; Fechheimer, Webber, \& Kleiber, 2011; Harsh, Maltese, \& Tai, 2011; Kardash, 2000; Lopatto, 2007; Russell, Hancock, \& McCullough, 2007; Schultz et al., 2011; Zydney, Bennett, Shahid, \& Bauer, 2002). This evidence helps us to suggest more confidently that minority training programs are effective in their mission to increase and diversify the STEM workforce through interventions featuring mentoring and research experiences. These programmatic solutions to broadening participation in STEM can be informed and enhanced by understanding how programs influence motivation to pursue distal scientific career goals.

\section{Motivation and STEM}

Motivational theories, such as social-cognitive career theory (Lent \& Brown, 1996) and expectancy-value theory (Eccles,1994; Eccles, Adler, \& Meece, 1984), have informed our understanding of career decision making in general and the leaky science degree pipeline problem in particular. Yet, goal theory can also uniquely inform our understanding of the leaky pipeline problem by focusing on the goals that give meaning and purpose to goaldirected activities (Covington, 2000). For example, research indicates that goal orientations are predictive of academic achievement, field choice, and persistence (Harackiewicz, Barron, Tauer, \& Elliot, 2002). Furthermore, goal theory can inform our understanding of the pursuit of multiple goals and the longitudinal maintenance of optimal motivation for success. However, research in goal theory has largely been conducted on White middle-class students, and this may limit generalizations to ethnically and culturally diverse populations (Pintrich, 1999). Furthermore, relatively little is known about the longitudinal regulation of achievement goals or the factors that encourage or sustain optimal motivation among college students (Fryer \& Elliot, 2007; Senko \& Harackiewicz, 2005), let alone underrepresented minority students majoring in STEM disciplines (Laursen, Hunter, Seymour, Thiry, \& Melton, 2010; Myers \& Pavel, 2011).

To extend our understanding of these issues, we addressed the leaky pipeline problem from a goal theory perspective by following African American and Latino undergraduate science students at 38 institutions over 3 academic years. In the current study, we examine two aspects of this process: (a) how environmental factors outside the classroom context (e.g., faculty mentorship) and person factors (e.g., scientific self-identity) contribute to the longitudinal regulation of achievement goal orientations and optimal motivation and (b) how goal orientations influence underrepresented science students' risk of "leaking out" of the scientific pipeline. We begin with a conceptual review of motivational concepts, follow with a review of goal orientations as predictors of academic choices and achievements, and conclude with a review of goal orientations as outcomes from environmental and person factors.

\section{Motivation}

The study of motivation has a long and rich history in psychology, with numerous paradigms attempting to define and explain the internal and external forces that push or pull individuals into action. Although there is disagreement about the precise nature of human motivation (Pintrich \& Schunk, 2002a), the current (generally cognitive) psychological approach has been to define motivation as "the process whereby goal-directed activity is 
instigated and maintained" (Pintrich \& Schunk, 2002a, p. 4). This definition is purposefully broad, as researchers from various psychological disciplines have posited numerous motivational constructs that give direction to, instigate, and maintain goal-directed activities (Kaplan \& Maehr, 2007; Pintrich \& Schunk, 2002a). Although the focus of this research is on goal orientations, there are numerous other influential motivational constructs from the social-cognitive paradigm, such as expectancies, values, and self-efficacy.

The most current and comprehensive model of how expectancies and values influence goaldirected activity across a variety of contexts has been posited by Eccles, Wigfield, and colleagues (e.g., Eccles et al., 1983). According to the theoretical model and empirical research, expectancies of success lead to deeper cognitive engagement on a task and higher levels of performance, whereas values influence the tasks an individual chooses to pursue (Eccles, Wigfield, Flanagan, \& Miller, 1989; Wigfield \& Eccles, 2000). Moreover, research has shown that expectancies and values influence academic and career choices and have been used to explain the underrepresentation of women and minorities in STEM disciplines (Battle \& Wigfield, 2003; Jacobs, 2005). Additionally, self-efficacy, a component of socialcognitive theory (Bandura, 1986), has become a particularly influential and parsimonious motivational construct for explaining the direction and maintenance of goal-directed activities. According to the theoretical model and empirical evidence, higher self-efficacy beliefs lead to higher levels of cognitive engagement, persistence, and actual performance (Bandura, 1986; Schunk, 1981, 1982, 1984). More recently, social-cognitive theory has been applied to understanding academic and career choices in majority and minority groups in STEM disciplines (Byars-Winston et al., 2010; Lent, Lopez, Sheu, \& Lopez, 2011).

\section{Goal Theory}

Unlike expectancy-value and social-cognitive theories, which attempt to describe and explain human behavior across a broad spectrum of contexts, goal theory has traditionally focused more narrowly on the reasons why students pursue achievements in a scholastic context (Covington, 2000; Kaplan \& Maehr, 2007; Pintrich \& Schunk, 2002a). Within goal theory, motivation is defined in terms of the goals that give purpose, meaning, and direction to achievement-related behaviors; consistent with the general cognitive approach, goals are characterized as internal events that draw individuals toward an activity (Shah \& Kruglanski, 2000). Thus, achievement goals can be conceptualized as internal cognitiveaffective schemas that frame why individuals engage in activities (E. M. Anderman \& Maehr, 1994; Elliott \& Dweck, 1988). The conception of achievement goal orientations and our understanding of the consequences of particular orientations have evolved over the past 30 years of research.

The current conception of achievement goal orientations distinguishes not only between mastery and performance goals but also between approach and avoidance orientations (Kaplan \& Maehr, 2007; Pintrich, 2000). Mastery goals (also known as learning or task goals) are defined as an individual's focus on developing competence, whereas performance goals are defined as an individual's focus on the demonstration of competence relative to others (Ames, 1992; Dweck, 1986; Nicholls, 1984). The approach orientation describes a focus on success; the avoidance orientation describes a focus on avoiding failure (Atkinson, 1957; Elliot \& Church, 1997; Elliot \& Harackiewicz, 1996). The approach-avoidance distinction was initially applied to performance goals, resulting in a trichotomous theoretical model: mastery goals (hereafter referred to as task goals); performance-approach goals, and performance-avoidance goals. ${ }^{1}$ The interpretation of mastery goals still refers to an individual's focus on developing competence, but performance-approach achievement goals are redefined as a person's focus on demonstrating competence relative to peers or a person's focus on competing against peers (Hulleman, Schrager, Bodmann, \& Harackiewicz, 2010). 
Performance-avoidance goals are redefined as a person's focus on avoiding demonstrating incompetence relative to peers (Covington, 2000). Therefore, the parsimonious goal theory model of motivation focuses on three beliefs that theoretically mediate the effect of environmental demands and person factors on achievement outcomes (E. M. Anderman \& Maehr, 1994).

\section{Goals as Predictors}

Consequences of goal orientations-Goal theory has grown in popularity in part because these goal orientations (i.e., mediating beliefs) predict and explain a broad range of proximal and distal achievement outcomes, such as learning strategies, level of cognitive engagement, affect, attributions, choices, and performance (for excellent reviews, see Covington, 2000, or Kaplan \& Maehr, 2007). Task goals are consistently linked to positive educational outcomes such as cognitive engagement, deep study strategies, persistence on difficult tasks, sustained interest, and academic performance among school-age students (Hulleman et al., 2010; Payne et al., 2007). Task goals are also related to continued interest, field choice, and persistence among college students (Harackiewicz, Barron, Tauer, \& Elliot, 2002). Performance-avoidance goals are consistently linked to negative educational outcomes such as self-handicapping, shallow learning strategies, and negative affect (Payne et al., 2007). The consequences of holding performance-approach goals appear to vary depending on their normative focus (competition against peers) or appearance focus (demonstrating competence relative to peers). As shown in a recent meta-analysis, items measuring the desire to demonstrate competence are negatively associated with performance outcomes; items measuring the desire to compete against peers are associated with positive achievement outcomes (Hulleman et al., 2010). Debate over the implications of holding or encouraging performance-approach goals culminated in researchers' shifting away from focusing on which goals are optimal versus detrimental to a focus on which goals are optimal under which circumstances (Harackiewicz, Barron, Pintrich, Elliot, \& Thrash, 2002).

The concept of optimal motivation has been particularly helpful for understanding how the pursuit of multiple goals may be advantageous. Real-world environments can be complex, and achieving success may require individuals to pursue multiple goals. The multiple goals perspective adopts the assumption that in educational settings, particularly at the college level, students who possess the goal to both develop mastery and best their peers are optimally motivated for success in complex and often competitive settings (Harackiewicz, Barron, Carter, Lehto, \& Elliot, 1997; Harackiewicz, Barron, Tauer, Carter, \& Elliot, 2000; Harackiewicz, Barron, Tauer, \& Elliot, 2002).

Therefore, it appears that motivational orientations favoring both task goals and performance-approach goals, yet eschewing performance-avoidance goals, are optimal for cultivating long-term educational success among college students. What is less well understood are the environmental factors and personal characteristics that support or engender the adoption and maintenance of optimal goal orientations over time.

\section{Goals as Outcomes}

\section{Goal adoption: The role of the environment, the person, and their congruence}

-Consistent with the social-cognitive paradigm, goal orientations are conceptualized as

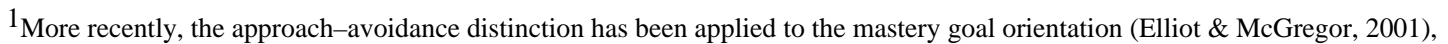
wherein mastery-approach goals are defined as above but mastery-avoidance goals describe a person's focus on avoiding deterioration in skill. However, consistent with most of the literature concerning the longitudinal regulation of achievement goals, the current study focuses on the trichotomous model of achievement goals.
} 
beliefs that mediate the effect of environmental and person factors on a variety of goaldirected activities (E. M. Anderman \& Maehr, 1994; Barron \& Harackiewicz, 2001a, 2001b; Dweck, 1986). Thus, much of the empirical research on when and why individuals adopt particular goal orientations has followed from one of two dominant perspectives (Kaplan \& Maehr, 2007): goals resulting from environmental cues (i.e., situated-schemas) or goals resulting from personal characteristics (i.e., self-schemas). Recent theorizing has also focused on the role of environment-person congruence, or fit, on motivation (Brodish \& Devine, 2009; Harackiewicz, Barron, \& Elliot, 1998; Jacobs \& Eccles, 2000; Smith, 2004).

The role of environment-From the early articulation of the theory through today, goal theorists have focused on the critical role of the environment on individual perception and meaning making (E. M. Anderman \& Maehr, 1994). According to goal theory, salient environmental cues prompt individuals to adopt congruent achievement goals for action on achievement-related tasks (Covington, 2000; Pintrich, 2000). For example, environmental cues, such as a teacher's or parent's focus on individual improvement, should prompt students to adopt task goals (Ames \& Archer, 1987, 1988). Institutional norms stressing competitiveness and scarcity of rewards should prompt students with high expectations of success to adopt performance-approach goals, and salient cultural norms of individualism and social comparison should prompt students with low expectations of success to adopt performance-avoidance goals (E. M. Anderman \& Maehr, 1994; Witkow \& Fuligni, 2007).

A large and methodologically diverse body of literature provides empirical support for the environmental cue hypothesis (Ames, 1992; E. M. Anderman \& Midgley, 1997; L. H. Anderman \& Anderman, 1999; Harackiewicz \& Elliot, 1998; Middleton, Kaplan, \& Midgley, 2004; Shim, Ryan, \& Anderson, 2008). Numerous cross-sectional and longitudinal studies have found that classroom-level goal structures tend to influence the adoption of congruent personal goal orientations (Ames, 1992; Pintrich \& de Groot, 1990). Additionally, environmental factors outside the classroom, such as socializing agents (e.g., parents and peers) or prevailing institutional, social, and cultural norms, can influence student goal orientations (Ames \& Archer, 1987; Duchesne \& Ratelle, 2010; Gonida, Voulala, \& Kiosseoglou, 2009; Maehr, 1991; Wentzel, 1998).

Research also indicates that the environmental factors external to the college classroom may play an important role in sustaining motivation to pursue STEM degrees and careers among underrepresented college students. For instance, evidence indicates that undergraduate participation in research or participation in mentoring programs appears to increase or sustain student motivation to pursue STEM careers among both majority and minority students (Hurtado, Cabrera, Lin, Arellano, \& Espinosa, 2009; Laursen et al., 2010; Lopatto, 2007; Villarejo, Barlow, Kogan, Veazey, \& Sweeney, 2008; Wilson et al., 2012). For example, a common finding in these studies is that undergraduate students who engage in research exhibit growth in scientific self-efficacy and scientific self-identity and develop more refined scientific career goals (Hurtado et al., 2009; Laursen et al., 2010).

Therefore, across all levels of education and from STEM or non-STEM disciplines, evidence appears to support the conclusion that motivation is sensitive to salient environmental features inside and outside the immediate classroom context. However, the specific link from research experience to goal orientations has not been the focus of much research. What little evidence exists must be inferred from qualitative research (Laursen et al., 2010) or studies that did not explicitly focus on goal orientations (Harsh et al., 2011; Lopatto, 2007). In these studies, researchers found that students and faculty mentors identified learning to cope with failure and frustration as important predictors of persistence in science. Students who learned to accept that failure was a normal part of the scientific process had better outcomes (Harsh et al., 2011). Similarly, minority students who learned to 
tolerate problems and who learned to see failed experiments as normal, rather than a reflection of their own inadequacies, had better outcomes. We suspect that these types of mentored and collaborative research experiences support growth in task goals and suppress growth in performance-avoidance goals; however, more research is required to substantiate these suspicions.

The role of person factors-A complementary approach in goal theory focuses on goals as personal dispositions or individual differences. From this perspective, relatively stable and enduring person factors dispose individuals to adopt aligned goal orientations, and therefore, the goal orientations themselves are relatively stable and enduring dispositions toward achievement (Covington, 2000). A variety of influential personality and individual difference factors are theoretical antecedents to goal adoption. For example, personality characteristics, such as the need for achievement or achievement motivation, should dispose individuals toward both task and performance-approach goals (Atkinson, 1957; Elliot \& Church, 1997; Payne et al., 2007); work-mastery orientation should dispose individuals toward task goals (Harackiewicz et al., 1997). Individual differences in self-theories or beliefs that individuals hold concerning themselves should influence the adoption of congruent goals (Covington, 2000). Finally, developmental, gender, and ethnic/racial differences may lead to the adoption of particular goal orientations that are stable across contexts and time (Pintrich \& Schunk, 2002b).

A large body of literature supports the hypothesis that salient person factors lead to the activation of congruent achievement goals (Covington, 2000; Dweck \& Leggett, 1988; Midgley et al., 1998). One focus of the current study is on the role of self-beliefs in determining goal orientations. We focus on salient self-beliefs because they have been found to play an important role in determining underrepresented students' integration and socialization into science (Estrada et al., 2011), but there is a gap in our understanding of how these beliefs influence the regulation of goals over time (Fryer \& Elliot, 2007).

One prominent line of research in the self-theory paradigm indicates that individual differences in implicit theories of intelligence (hereafter referred to as mindset) cause the adoption of congruent achievement goals (Dweck, 1986; Dweck \& Leggett, 1988; Elliott \& Dweck, 1988). Research indicates that holding the mindset that ability or intelligence is fixed (i.e., fixed mindset or entity mindset) leads to a performance-avoidance goal orientation when individuals have low expectations of success but leads to performanceapproach goal orientations when expectations are high. In contrast, holding the belief that ability or intelligence is malleable (i.e., incremental mindset) leads to a task goal orientation regardless of success expectations. However, the role of mindset on the longitudinal stability (or change) of goal orientations in adulthood has not yet received much attention (Fryer \& Elliot, 2007).

Another focus of this research is the role of domain identity (or identities) on motivation. Recent work has sought to understand how salient identities influence goal orientations and vice versa (Kaplan \& Flum, 2009; Kaplan \& Maehr, 2007; McCaslin, 2009; Wigfield \& Wagner, 2005). For example, research on stereotype threat indicates that salient negatively stereotyped identities activate performance-avoidance goals, which in turn produce negative consequences on achievement (Brodish \& Devine, 2009; Smith, 2006; Smith, Sansone, \& White, 2007). Although stereotype threat is not the focus of this paper, these findings imply that salient identities can influence the adoption of achievement goal orientations.

A salient identity of particular interest in STEM and for underrepresented students in STEM has been the centrality of a person's identity as a scientist. Recent work indicates that the centrality of scientific identity facilitates underrepresented students' integration into the 
sciences (Chemers et al., 2010; Estrada et al., 2011). Thus, salient positive identities, such as scientific identity, may operate in a similar manner as threatened identities (i.e., by activating task goals that lead to associated positive outcomes); however, there is a paucity of empirical research linking salient identities to adoption of congruent achievement goals (Roeser \& Lau, 2002; Wigfield \& Wagner, 2005). Thus, we hypothesize that scientific identity should have a strong influence on the adoption of congruent and optimal task goals.

Goal orientations in minority samples-Theory and research have substantially advanced our knowledge of the person factors that influence achievement goal adoption. However, studies have largely been conducted on White middle-class students, which may limit generalizations to ethnically and culturally diverse populations (Maehr \& Meyer, 1997; Pintrich, 1999).

Researchers have begun to address this gap, but most of this small body of literature has focused on students in primary and secondary school (Brown-Wright \& Tyler, 2010; Friedel, Cortina, Turner, \& Midgley, 2010; Gutman, 2006; Stevens, Hamman, \& Olivárez, 2007; Tyler et al., 2010; Wilkins \& Kuperminc, 2010). Although motivation in the primary grades is certainly important, we also need to understand the motives and goals of students in a college context if we are to address the leaky pipeline issue. Thus, goal theory can benefit from a focus on college-age minority students' goals and the impact those goals have on field choice and persistence, particularly in STEM disciplines. Our study directly addresses this gap in the literature between minority students' goal orientations and persistence in the STEM pipeline.

Congruence of environmental and person factors-Research indicates that in addition to their independent effects, environmental and person factors in congruence influence achievement goal adoption and optimal motivation (Barron \& Harackiewicz, 2001a, 2001b; Lockwood, Jordan, \& Kunda, 2002). For example, research indicates protégés experienced the highest level of success when mentors and protégés expressed congruent learning goal orientations (Egan, 2005; Godshalk \& Sosik, 2003).

Most of the current research has focused on how environmental or person factors influence the initial adoption of achievement goals rather than on the longitudinal regulation of such goals in the pursuit of a distal goal. Further, relatively little research has focused on the longitudinal regulation of achievement goals among college students or among minority students.

\section{Goal Adoption to Goal Regulation}

Stability over time-For the most part, researchers have assumed that achievement goals remain stable over time (Fryer \& Elliot, 2007; Senko \& Harackiewicz, 2005). A small number of studies have empirically tested these assumptions. Researchers have studied the temporal stability of achievement goals within a single domain (e.g., mathematics; Fryer \& Elliot, 2007; Meece \& Miller, 2001; Senko \& Harackiewicz, 2005) and across multiple domains (e.g., general goals in school; E. M. Anderman \& Midgley, 1997; L. H. Anderman $\&$ Anderman, 1999; Middleton et al., 2004; Shim et al., 2008). In general, longitudinal studies indicate that achievement goals exhibit only moderate temporal stability over time. Evidence also indicates that individual-level changes in goal orientations can be masked by mean-level stability of goals over time (Fryer \& Elliot, 2007). Thus, it appears that some factors may lead to systematic changes in goal orientations over time at both the mean and individual levels. 
Changes in goals over time-A few studies have examined the longitudinal regulation and changes of achievement goals within a single content domain over time, such as mathematics (Fryer \& Elliot, 2007; Grant \& Dweck, 2003; Senko \& Harackiewicz, 2005; Zusho, Pintrich, \& Coppola, 2003), or across multiple content domains over time, such as English and mathematics (E. M. Anderman \& Maehr, 1994; L. H. Anderman \& Anderman, 1999; Shim et al., 2008; Wilkins \& Kuperminc, 2010). In general, these studies indicated that task goals tend to decline over time, whereas performance-approach and performanceavoidance goals show a less predictable pattern of change. Furthermore, research indicates that changes in goal orientation are moderated not only by goal structures and competence feedback (i.e., environmental factors; Fryer \& Elliot, 2007; Senko \& Harackiewicz, 2005) but also by individual differences in ability and social belonging (E. M. Anderman \& Midgley, 1997; L. H. Anderman \& Anderman, 1999).

Although these longitudinal studies provide useful information about the regulation of goals over time, many of the studies were methodologically limited due to measuring goals over a relatively short period of time, such as a single semester, and substantively limited due to including a small number of potentially important explanatory factors. Additionally, only a small number of potentially relevant environmental and person factors have been investigated to determine their role in supporting optimal motivation over time among college students. Many studies examining the longitudinal regulation of goals focused on environmental factors within the classroom context; however, research has shown that environmental factors from outside of the classroom context can be important ones for adopting achievement goals (e.g., school climate or socializing agents). Finally, research has also shown that person factors, such as mindset, can play an important role in goal adoption, yet there is currently limited information about the role this factor plays on the regulation of goals over longer periods of time.

In summary, there is a national priority for increasing and diversifying the STEM workforce. Interventions, such as minority training programs, mentoring, and research experiences, appear to help ameliorate the leaky pipeline problem by sustaining student interest in STEM (Denofrio, Russell, Lopatto, \& Lu, 2007; Lopatto, 2007; Pfund et al., 2006; Russell et al., 2007). We suspect that these types of college experiences have an effect on sustained interest, in part because they alter or sustain the student's optimal motivation (i.e., goal orientations) over time. However, there is a paucity of research on the variety of environmental factors (e.g., research experiences) and person factors that may influence the regulation of achievement goals (e.g., mindset and identity). Furthermore, there is limited research on the longitudinal impact goal orientations on persistence in STEM disciplines among underrepresented minority college students.

\section{Current Study}

In the current paper, we sought to address the gaps in knowledge about the longitudinal regulation of achievement goals and their impact on persistence within a larger investigation of the leaky pipeline problem in the STEM disciplines. The current study-

TheScienceStudy—reports on a longitudinal panel of talented and high-achieving, underrepresented students in the STEM disciplines attending universities across the United States. One of the primary goals of TheScienceStudy is to follow these high-achieving, underrepresented students through the academic pipeline from the undergraduate years, through graduate school, and into the professional working world. Furthermore, a large proportion of the participants are or were enrolled in one of many minority training programs as well as common undergraduate-science-related activities, such as working with a faculty mentor and engaging in scientific research. 
Our specific goals in this report were to examine the effect of environmental and person factors on the goal orientations of underrepresented students in STEM over an extended period of time and to examine the impact of these goals on students' performance and persistence in STEM fields. However, because we measured goal orientations with the Patterns of Adaptive Learning Scales (PALS) and because our sample consisted of students from first through fourth years in college, we cannot be sure that the students interpreted the goals items as being directed at an exclusively STEM-oriented experience. Therefore, the goal orientations measured in this study represent dispositional achievement goals toward school rather than achievement goals toward science specifically. Our inferences are about how engagement in common extracurricular activities in STEM influence a general motivational disposition, rather than a specific motivation toward science.

Our first set of hypotheses concerned goals as outcomes. We hypothesized the following patterns of growth in the goal orientations:

1. The unconditional (i.e., no predictors in the model) pattern of growth will be consistent with prior research among majority samples (i.e., average decline in mean-level task goals, average stability of mean-level performance-approach goals, and average increase in mean-level performance-avoidance goals), but there will be substantial individual-level variability in intercept and growth trajectories for performance-approach goals.

2. Consistent with prior research in college samples, baseline grade point average (GPA) would predict initial performance-approach goals; however, we did not predict differences in goal orientation growth factors based on gender (i.e., female vs. male) or minority status (i.e., African American vs. Latino).

3. Minority training program status, faculty mentorship status, and research experiences were predicted to positively influence initial task goals and growth in task goals.

4. Initial science identity and growth in science identity would positively influence task goals.

5. Holding a relatively fixed mindset would predict initial performance-approach and performance-avoidance goals and would positively influence growth in the performance goals.

Our second set of hypotheses concerned goal orientations as predictors of student achievements. Consistent with prior research, particularly among college samples in STEM fields and among minority students, the following patterns of results were hypothesized:

6. Task and performance-approach goals would positively influence final undergraduate GPA over and above the influence of baseline GPA.

7. Task goals would positively predict persistence in the student's original STEM major.

8. For those who changed their original major, task goals would positively predict persistence in a STEM discipline.

\section{Method}

\section{Participants}

As described previously, participants were members of TheScienceStudy, a longitudinal panel study of 1,420 racially and ethnically diverse science undergraduate and graduate 
students recruited from universities and colleges across the United States. A primary goal in TheScienceStudy was to follow underrepresented science students through the academic pipeline. The initial panel of college students was recruited to participate in the study in the fall of $2005(n=1,053$, Wave 0$)$, and panel members were added in the fall of 2006 ( $n=$ 312 , Wave 2) and fall of $2007(n=55$, Wave 4).

The current study focused on the goal orientations of African American and Latino undergraduates majoring in a STEM discipline over 3 academic years, from the spring of 2006 (Wave 1) through the spring of 2008 (Wave 5). Therefore, the sample consists of 1,046 African American $(n=594)$ and Latino $(n=452)$ undergraduate students from 38 universities. At the time of enrollment, the African American students were primarily female (77\%), in their early twenties $(M=20.96, S D=3.06)$, and completing their junior or senior year in college (58\%). Further, $16 \%$ of the African American participants were the first generation to attend college or did not know their parents' educational attainment (9\%), and a larger proportion had at least one parent who had attended college (some college $=21 \%$, associate's degree $=10 \%$, baccalaureate degree $=22 \%$, graduate or professional degree $=$ $22 \%)$. Similarly, the Latino students were primarily female (67\%), in their twenties ( $M=$ 21.61, $S D=3.78)$, and completing their junior or senior year in college $(73 \%)$. Further, $23 \%$ of the Latino participants were the first generation to attend college or did not know their parents' educational attainment (6\%), and a larger proportion had at least one parent that had attended college (some college $=18 \%$, associate's degree $=8 \%$, baccalaureate degree $=$ $21 \%$, graduate or professional degree $=18 \%$ ).

\section{Procedure}

Participants responded to biannual (fall and spring) online surveys concerning their educational status (e.g., college senior majoring in chemistry), educational and professional aspirations (e.g., intention to pursue a graduate degree in a scientific discipline), engagement in scientific activities (e.g., participation in lab research), and status on a number of theoretically relevant individual differences (e.g., achievement goal orientations). Participants received a small incentive for their participation in the study ( $\$ 25$ per survey). The current study reports on data surveyed across 3 academic years, from spring 2006 (Wave 1) to spring of 2008 (Wave 5). We specifically chose a 3-year window because the majority of the undergraduate sample would have graduated after 3 academic years.

\section{Instrumentation}

Task goal orientation-The PALS Task Goal Orientation subscale consisted of six items that ask students to rate their agreement with statements regarding their motivation to develop abilities and skills (e.g., "I like school work that I'll learn from, even if I make a lot of mistakes") on a 5-point scale from 1 (Strongly Disagree) to 5 (Strongly Agree; Midgley et al., 1998). A meta-analytic review of this scale among college samples indicated that the mean internal consistency reliability was $\alpha=.80$ (Ross, Blackburn, \& Forbes, 2005).

Performance-approach goal orientation-The PALS Performance-Approach subscale consisted of six items that ask students to rate their agreement with statements regarding their motivation to compete against and to demonstrate abilities relative to their peers (e.g., "It's important to me that the other students in my classes think that I am good at my work") on a 5-point scale from 1 (Strongly Disagree) to 5 (Strongly Agree; Midgley et al., 1998). A meta-analytic review of this scale among college samples indicated that the mean internal consistency reliability was $\alpha=.85$ (Ross et al., 2005). Additionally, in light of a recent meta-analysis, it is important to note that the PALS Performance-Approach scale has a mix of items related to normative and appearance goals (Hulleman et al., 2010). 
Performance-avoidance goal orientation-The PALS Performance-Approach subscale consisted of six items that ask students to rate their agreement with statements regarding their motivation to avoid demonstrating a lack of abilities and skills (e.g., "It's very important to me that I don't look stupid in my classes") on a 5-point scale from 1 (Strongly Disagree) to 5 (Strongly Agree; Midgley et al., 1998). A meta-analytic review of this scale among college samples indicated that the mean internal consistency reliability was $\alpha=.83$ (Ross et al., 2005).

Although the content of task, performance-approach, and performance-avoidance goal items were originally developed for use in primary grades, this scale has been successfully applied in college settings (Ross, Shannon, Salisbury-Glennon, \& Guarino, 2002). Therefore, we kept item content consistent with prior studies in college samples. Furthermore, given that the original items refer to goals toward "school" rather than goals toward "science" or a specific class, student responses refer to more general dispositional goals. This operationalization will inform on students' general motivation toward academic achievement in school contexts. Item contents are listed in the Appendix. The PALS goal orientation subscales were administered at four measurement occasions (spring 2006 [Wave 1], fall 2006 [Wave 2], spring 2007 [Wave 3], and spring of 2008 [Wave 5]).

Minority training program status-A number of the participants were enrolled in minority training programs (MTP) for underrepresented students in STEM disciplines. At each wave of data collection, students were asked, "Are you currently enrolled in a minority training program at your college?" Responses at each wave of data collection were dummy coded into the MTP variable: $0=$ non MTP member, and $1=$ MTP member. The MTP variable was coded as a time-varying covariate to model the persistent effect of minority training programs on goal orientations (McCoach \& Kaniskan, 2010). For example, students who were continuously enrolled in a training program would have a score profile of $1,2,3$, 4,5 ; students who were not enrolled in a training program would have a score profile of 0,0 , $0,0,0$. Finally, students who transitioned to and stayed continuously enrolled in a minority training program in the third wave of data collection would have a score profile of $0,0,1,2$, 3.

Faculty mentorship-At each wave of data collection, students were asked if there was a faculty member whom they considered to be a mentor. Student responses were dummycoded into the faculty mentor variable: $0=$ does not have a faculty mentor, $1=$ has a faculty mentor. As above, the faculty mentorship variable was coded as a time-varying covariate to model the persistent effect of mentorship on goal orientations over time. For example, students who reported having a mentor for the three consecutive semesters (spring 2007 through spring 2008) would have a score profile of $0,0,1,2,3$.

Research experience-At each wave of data collection, students were asked if they had experience with "Hands-on research activities with laboratory equipment in class," had "Worked in a laboratory" at their current or other university, or had "Worked on research at another location." Student responses were dummy-coded into the research experience variable: $0=$ no research experiences; $1=$ research experience. As above, the research experience variable was coded to show the persistent effect of research experience. For example, students who reported having engaged in research experiences at all points over the 3 academic years would have a score profile of 1, 2, 3, 4, 5 .

Mindset-Mindset (i.e., implicit theory of intelligence) was measured with three items (Dweck, Chiu, \& Hong, 1995a; 1995b). On a 5-point scale from 1 (Strongly Disagree) to 5 (Strongly Agree), students rated the extent to which they agreed with the following 
statements: "You have a certain amount of intelligence, and you can't do much to change it," "Your intelligence is something that you can't change very much," and "You can learn new things, but you can't really change your basic intelligence." High scores indicate that the individual views intelligence as fixed (i.e., fixed mindset), and low scores indicate that the individual views intelligence as malleable (i.e., growth mindset). Prior studies show that scores exhibited high internal consistency reliability (as $=.94$ to .98 ) and high test-retest reliability over a 2-week period ( $r=.80$; Dweck et al., 1995b). This scale was administered at three measurement occasions (spring 2007 [Wave 3], fall 2007 [Wave 4], and spring of 2008 [Wave 5]).

Scientific identity-Scientific identity was measured with five items (Estrada et al., 2011). Students were asked to assess to what extent each statement was true of them on a scale from 1 (Strongly Disagree) to 5 (Strongly Agree). Items included statements such as "I have a strong sense of belonging to the community of scientists" and "The daily work of a scientist is appealing to me." A prior study indicated that scores among undergraduate students exhibited high internal consistency reliability ( $\alpha=.87$; Estrada et al., 2011). This scale was administered at three measurement occasions (spring 2006 [Wave 1], fall 2006 [Wave 2], and spring 2007 [Wave 3]).

Baseline GPA—Prior to enrollment in this study, participants completed a screening survey in which students were asked to report their current cumulative college GPA. Undergraduate student responses to this question were coded into the baseline GPA variable $(M=3.27, S D=0.43, n=958)$.

Final GPA-At each wave of data collection, students were asked to report their current cumulative college GPA. Participants' final responses to this question during their undergraduate tenure were coded into the final GPA variable $(M=3.21, S D=0.46, n=$ 922).

Persistence in major-Prior to enrollment in this study, participants completed a screening survey and reported their major field of study. Response options included "Behavioral Sciences" (9.2\%), "Biological Sciences" (63.9\%), "Engineering" (2.3\%), "Mathematics or Computer Science" (2.9\%), "Natural Sciences" (20.4\%), and "Social Sciences" (1.4\%). At each subsequent wave of data collection, participants reported if they had changed their major or if they remained in the same field of study. Student responses were dummy-coded into the persistence in major variable $(n=923)$ : $0=$ changed major $(15.9 \%) ; 1=$ persist in major $(84.1 \%)$.

Persistence in STEM-Students who did change their undergraduate major were asked to report their new major field of study. Response options included "Behavioral Sciences," "Biological Sciences," "Engineering," "Mathematics or Computer Science," "Natural Sciences," "Social Sciences," and "Other (please specify)." The Other option allowed participants to write in their new major, and those responses were screened for sciencerelated majors (e.g., "premed") and non-science-related majors (e.g., "education" or "social work"). All student responses were then dummy-coded into the persistence in STEM variable $(n=923)$ : $0=$ changed to non-STEM major $(7.7 \%) ; 1=$ persisted in a STEM major $(92.3 \%)$. The behavioral sciences, biological sciences, engineering, mathematics or computer science, natural sciences, social sciences, and all other majors that were STEMrelated (e.g., premed) were included in the persisted in STEM group. 


\section{Plan of Analysis}

All analyses were conducted in a structural equation modeling framework. Full information maximum likelihood estimation in Mplus version 6.1 (Muthén \& Muthén, 1998-2009) was used to complete the analyses with continuous outcomes, and weighted least squares estimation in Mplus version 6.1 was used to complete the analyses with dichotomous outcomes (i.e., persistence). In addition to the model $x^{2}$, the following indices were used to evaluate model fit (Hu \& Bentler, 1998): comparative fit index (CFI), root-mean-square error of approximation (RMSEA), and standardized root-mean-square residual (SRMR). Further, when nested models were compared, the $x^{2} \delta$ test was used to evaluate misfit (Kline, 2005). The following cutoffs for indicating good fit were adopted a priori: CFI values at or above .95; RMSEA values at or below .05 (or a $90 \%$ confidence interval that included .05 but did not include .10); SRMR values at or below .06; and when comparing nested models, nonsignificant $\mathrm{X}^{2} \Delta$ values.

\section{Results}

\section{Goals as Outcomes}

Measurement models-We first tested the cross-ethnic and longitudinal measurement invariance of the instruments in our study (Brown, 2006; Hui \& Triandis, 1985). A series of confirmatory factor analyses revealed that all scales exhibited scalar level cross-ethnic and longitudinal measurement invariance (see Table 1; also see the Appendix for goal orientation items retained through the series of CFAs and see supplemental materials for all intermediate confirmatory factor analysis models, the latent correlation matrix, as well as the descriptive statistics for the goal orientation and the predictors variables). These findings indicate that the African American and Latino students were interpreting items and using the response scales in the same way, both across groups and within groups over time.

Models 1 and 2: Null and unconditional growth-We proceeded to model the influence of background, environmental, and person factors (i.e., Hypotheses 1-5) on the regulation of task, performance-approach, and performance-avoidance goal orientations using latent parallel process growth modeling to account for interdependence of the growth processes. The purposes of Models 1-2 were to estimate the intraclass correlation, which quantifies the proportion of variability in goal orientation scores due to within-person variability (i.e., $\sigma^{2}$ ) and between-person variability (i.e., T; Hox, 2002; Raudenbush \& Bryk, 2002), ${ }^{2}$ and to identify a growth model that provides the best fit to the student's goals over time (Model 2).

The series of models provided acceptable fit to the data (see Table 2; M1-M2). They indicated that $50-61 \%$ of variability in goal orientation scores was between students, and $39-50 \%$ of the variability was within students (see supplemental materials for details of

\footnotetext{
${ }^{2}$ Because we collected data from students enrolled in numerous institutions of higher learning $(N=38)$, we first attempted to fit the data to a three-level, parallel process latent growth curve model. However, the analysis revealed that the average intraclass correlation coefficient for task, performance-approach, and performance-avoidance goal orientations was extremely small. The small proportion of between-school variance resulted in estimates of intercept and slope variance at Level 3 that approached zero and caused model convergence problems. For example, the unconditional three-level latent growth curve model resulted in the following estimates of variance components: task goals $=0.188$ (within-person), 0.247(Level 2 intercept), 0.005(Level 2 slope), 0.007 (Level 3 intercept), and 0.000 (Level 3 slope); performance-approach goals = 0.388 (within-person), 0.703 (Level 2 intercept), 0.022 (Level 2 slope), 0.033 (Level 3 intercept), and 0.000 (Level 3 slope); performance-avoidance goals $=0.572$ (within-person), 0.569 (Level 2 intercept), 0.009 (Level 2 slope), 0.015 (Level 3 intercept), and 0.000 (Level 3 slope). Furthermore, through a series of exploratory model constraints, we found that the model only became stable (i.e., converged) once all Level 3 variance components (except the intercept of performance-approach goals) were fixed to zero. However, progressing with conditional three-level latent growth curve models was prohibited by the complexity of the analysis (i.e., large number of parameter estimates associated with parallel process growth models, time-varying, and time-invariant predictors) and the small number of Level 3 observations $(N=38)$. Therefore, we proceeded with a two-level latent growth curve model of the goal orientations.
} 
variance components for the null model). Therefore, both within- and between-student factors may play important roles in explaining variability in goal orientation scores.

Further, the analyses revealed that the linear growth model improved fit compared to the intercept only model, $\mathrm{X}^{2} \Delta(8)=30.80, p<.001,{ }^{3}$ and revealed an informative pattern of correlations among the latent intercept and growth factors (see supplemental materials for a figure depicting this model). An examination of fixed effects indicated that on average, task goals started relatively high (i.e., 4.28 out of 5.00) and tended to decline at a small but not statistically significant rate (i.e., -0.02 ; see Table 4, M2); however, the latent variances (i.e., random effects) indicated significant variability around the average starting point (i.e., 0.256) and growth slope (i.e., 0.005; see Table 3, M2). Similarly, average performanceapproach goals started moderately high, declined at a small and nonsignificant rate, and exhibited significant variability around the starting point and growth slope. Performanceavoidance goals, on the other hand, started relatively low, did not change over time, and exhibited significant variability only around the average starting point. Thus, environmental and person factors may play an important role in explaining both the residual within-student and between-student variability in where students start (i.e., intercepts) and how they grow (i.e., growth slopes).

Finally, although the pattern of relationships between the intercepts was consistent with theory and prior research, the correlations between the growth slope factors revealed a novel pattern of relationships. The growth slope of task goals was moderately and positively correlated with growth in performance approach, which indicates that students who expressed an increasing desire to develop competence also expressed an increasing desire to compete against and demonstrate their competence relative to their peers (see Table 3, M2). This finding hints at growth toward optimal motivation over time among underrepresented minority students in STEM.

Models 3-5: Conditional growth-The purposes of Models 3-5 were to control for the influence of prior achievement and background characteristics on the growth trajectories (Model 3) and to test the effects of environmental factors (Model 4) and personal factors (Model 5) on the goal orientation growth processes ${ }^{4}$.

Impact on intercepts (initial goals)-The series of models provided acceptable fit to the data (see Table 2, M3-M5). Further, the models revealed that the background characteristics of baseline GPA and African American status predicted intercepts of the achievement goals; revealed that research experience was the only contextual factor that uniquely predicted the achievement goals, ${ }^{5}$ and revealed that the mindset growth process predicted performance-approach and -avoidance goals and that the science identity growth processes predicted task and performance-approach goals ${ }^{6}$ (see Table 4, M3-M5). The final model (i.e., Model 5) revealed that baseline GPA exhibited a small positive relationship with

\footnotetext{
${ }^{3}$ As with the intercept only model, we first attempted to freely estimate all latent variances; however, the initial model failed to achieve convergence because the variance of the performance-avoidance growth slope approached zero. This result indicated that there was no appreciable individual-level variability around the mean linear growth slope. Therefore, the model was rerun with the variance of the performance-avoidance growth slope constrained to zero.

${ }^{4}$ To evaluate the effect of these individual differences on goals over time, we sequentially entered baseline GPA (centered at the grand mean), African American status (with weighted effect coding), and female status (with weighted effect coding) variables into the model as time-invariant predictors of the intercepts and linear growth slopes, with nonsignificant paths sequentially trimmed from the model. Because female status exhibited no statistically significant effects, this variable was trimmed from the final model (M3). To evaluate the effect of environmental factors on goal orientations over time, we sequentially entered minority training program status, faculty mentorship, and research experience variables as time-varying predictors of the repeated measures of goal orientations, controlling for the effect of African American status and baseline GPA on training program status, mentorship, and research experiences. To evaluate the effect of the person factors on goal orientations over time, we sequentially entered the parallel latent growth processes of science identity and mindset as predictors of the intercept and growth slopes of the goal orientations, controlling for the effect of African American status and baseline GPA on identity and mindset.
} 
initial task goals and that African American students exhibited higher initial performanceavoidance goals than did their Latino counterparts. Additionally, the model revealed that the latent intercept of the mindset construct exhibited a moderate positive relationship to initial performance-approach and performance-avoidance goals, and the latent intercept of the science identity construct exhibited a large positive relationship to initial task goals and a small positive relationship with initial performance-approach goals.

Overall, these findings indicate that African Americans in STEM may be at a relatively higher risk of experiencing the negative cognitive, emotional, and behavioral consequences of holding performance-avoidance goals. Furthermore, individuals holding a fixed view of intelligence may be at a relatively higher risk of experiencing the negative consequences associated with performance-avoidance goals.

Impact on growth slopes-After adjusting for the effects of research experiences and growth in science identity, the model indicated that students with no research exhibited small but statistically significant positive growth in performance-approach and performanceavoidance goals over time (see Table 4, M5). However, research activities buffered students from this maladaptive increase in performance-avoidance goals as well as the increase in performance-approach goals. Although research experiences initially exhibited a positive influence on growth in task goals, the entry of growth in science identity produced a suppressor effect on the relationship. Additionally, the model revealed that the latent growth slope of the science identity exhibited large positive effects on growth in task and performance-approach goals.

Overall, these findings were encouraging, as the vast majority of African American and Latino students reported engaging in one or more research activities over time. However, for a small segment of the sample, either avoidance of or lack of opportunity to engage in common undergraduate research activities put them at a relatively higher risk of experiencing the negative consequences of holding performance-avoidance goals. Furthermore, growth in scientific identity appears to have focused students on both developing competence and competing against or demonstrating competence relative to their peers.

\section{Goals as Predictors}

Next, we modeled the effects of goal orientations on distal student outcomes final GPA and persistence in STEM (i.e., Hypotheses 6-8). To evaluate the effect of goals on distal academic achievements, we sequentially entered the goal orientation growth factors (i.e., intercepts and linear growth slopes) as predictors of student outcomes, after controlling for African American status, female status, and baseline GPA.

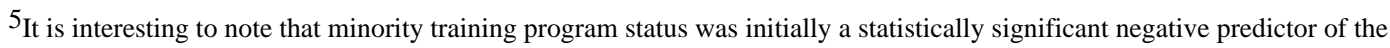
performance-approach goals $(b=-0.09, S E=0.03, p=.004)$; however, when research experience was added into the model, training program status dropped out as predictor. This finding hinted at a mediational process, whereby the effects of minority training programs were mediated through a key program feature (i.e., research experiences). This hypothesis should be more thoroughly tested in future research.

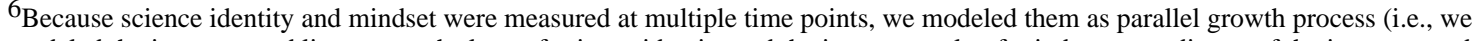
modeled the intercept and linear growth slope of science identity and the intercept only of mindset as predictors of the intercept and growth slopes of the goal orientations; see supplemental material for details of determining the form of the growth processes). Because time was centered at Wave 1 for science identity, we interpreted that intercept as the mean science identity at Wave 1 . Furthermore, because mindset was an intercept-only model, we interpreted the intercept of mindset as the mean score for all students at all time points (i.e., Waves 3, 4, and 5). Further, as shown in Table 5, after accounting for linear growth in science identity, the variance linear growth of task goals was estimated as 0.000 , which causes convergence problems. Therefore, the variance of the linear growth slope of task goals was constrained to zero.
} 
GPA-First, we examined the impact of goal orientations on final cumulative undergraduate GPA. Final GPA exhibited significant variability between persons and between schools; ${ }^{7}$ therefore, we modeled final GPA at two levels (i.e., between students and between schools). The final trimmed model provided good fit to the data (see Table 2, M6). Furthermore, the model revealed that, contrary to our hypothesis and prior research, only the intercept of task goals positively predicted final GPA $\left(b_{\text {between-persons }}=0.07, S E=.02, \beta=\right.$. $08, p=.003$ ), over and above the strong effect of baseline GPA at the between-person and between-school levels $\left(b_{\text {between-person }}=0.72, S E=.03, \beta=.70, p<.001 ; b_{\text {between-schools }}=\right.$ $0.87, S E=.16, \beta=.85, p<.001)$.

Persistence in original STEM major and in STEM-Next, we examined the impact of goal orientations on student persistence in their major and, for those who changed majors, persistence in STEM. However, unlike final GPA, our measures of persistence did not exhibit significant variability between-schools. ${ }^{8}$ Therefore, persistence in major and in STEM was only modeled between persons.

Student persistence in their original STEM major was regressed on the control variables (i.e., baseline GPA, African American status, and gender) and goal orientations. The final trimmed model provided good fit to the data (see Table 2, M7). Further, the probit regression revealed that, contrary to our hypothesis, only the intercept of performanceavoidance goals influenced persistence $(b=-0.19, S E=.08, p=.02)$, over and above the effect of baseline GPA $(b=0.23, S E=.12, p=.05)$. To make these findings more concrete, we derived the predicted probability of persistence for students with relatively high, average, and relatively low initial performance-avoidance goals (e.g., $\pm 1 S D$ performance-avoidance goals), controlling for other factors in the model. Students expressing average performanceavoidance goals had an $86 \%$ probability of persisting in their initial STEM major, those expressing higher avoidance goals had a $79 \%$ probability of persisting, and those expressing lower avoidance goals had an $89 \%$ probability of persisting.

Next, student persistence in STEM was regressed on the control variables and goal orientations. The final trimmed model provided good fit to the data (see Table 2, M8), and probit regression revealed that, contrary to our hypothesis, only the intercept of performance-avoidance goals influenced persistence $(b=-0.22, S E=.09, p=.01)$. As above, we derived the predicted probability of leaving STEM for students with relatively high, average, and low initial performance-avoidance goals. Students expressing average performance-avoidance goals had a $93 \%$ probability of persisting in a STEM discipline; those expressing higher avoidance goals had an $89 \%$ probability of persisting, and those expressing lower avoidance goals had a $96 \%$ probability of persisting.

Integrating these results, we find that contextual factors (research experiences) and individual differences (mindset and scientific self-identity) exert influence on individuals' achievement goals, over and above background characteristics and prior achievement. Achievement goals, in turn, exert influence on students' long term academic achievement and persistence in STEM, even after controlling for background characteristics and prior achievement. For example, individuals with lower engagement in research experience exhibited higher performance-avoidance goals (Model 4), and individuals with higher performance-avoidance goals were more likely to change their original major and were more likely to abandon STEM majors (Models 7 and 8). Additionally, individuals who

\footnotetext{
${ }^{7}$ Variability between-persons variance $\left(\mathrm{T}_{\Pi}=0.195, S E=0.01, p<.001\right)$ and between-schools variance $(\mathrm{T} \beta=0.016, S E=0.007, p=$. 02).

${ }^{8}$ Between-school variability for persistence in original major $(\mathrm{T} \beta=0.000, S E=0.002, p=.88)$ and persistence in any STEM discipline ( $\mathrm{\top} \beta=0.14, S E=0.14, p=.34)$
} 
experienced positive growth in their self-identity as scientist exhibited positive growth in their task goals (Model 5), and individuals with higher task goals exhibited higher academic performance, controlling for prior performance (Model 6).

\section{Discussion}

There is a growing national interest in understanding the factors that sustain motivation for STEM careers, particularly for underrepresented minority groups that tend to leak out of the STEM pipeline (Myers \& Pavel, 2011). Our purpose in the current study was to investigate the leaky pipeline problem from a goal theory perspective. Studies of intervention programs focused on broadening participation in STEM often show the positive impact of undergraduate research and mentoring experiences on retaining underrepresented students in STEM; however, these studies often ignore the role of goals and other social-cognitive beliefs that mediate the relationship between the intervention and key outcomes (Lopatto, 2007; Maton \& Hrabowski, 2004; Maton et al., 2009). Additionally, studies examining the role of goal orientations have typically focused on the educational achievements and experiences of middle-class White students (Pintrich, 1999). Thus, the current study was an attempt to bridge the gap between the broadening participation and goal theory literatures.

We followed the educational achievements and aspirations of high-achieving African American and Latino undergraduates over 3 academic years. At the time of enrollment in this study, all students were majoring in a STEM discipline, primarily in the biological or physical sciences; all students reported an interest in pursuing a scientific research career; many of the students were enrolled in extracurricular minority training programs aimed at broadening participation in the sciences (e.g., Research Initiative for Scientific Enhancement); and the majority were in the latter years of their undergraduate education. Given the composition of the sample and national trends toward exposing students to undergraduate research (Laursen et al., 2010; Lopatto, 2007), we expected that many of the participants would have a faculty mentor and engage in research experiences (i.e., environmental factors). Further, given that engagement in these types of experiences has been shown to influence science self-efficacy, scientific identity, and adoption of cultural norms and values of the scientific community (Estrada et al., 2011; Laursen et al., 2010), we expected to find shifts in how students perceived themselves (i.e., scientific self-identity and mindset). We hypothesized that growth in environmental and individual difference factors would influence the longitudinal regulation achievement goals, and achievement goals would, in turn, influence academic performance and persistence in STEM.

\section{Factors Influencing the Regulation of Achievement Goals}

The key findings of this study indicated that increasing engagement in research experiences and growth in scientific self-identity affected growth in task and performance-approach goals, while they buffered students from growth in performance-avoidance goals. We found that students engaged in research activities, either inside or outside the classroom, exhibited a small decline in performance-avoidance goals toward school over time, whereas those not engaged in research exhibited an increase in these goals over time. This finding was consistent with prior studies showing that the goal of "not failing" is incongruent with the daily practice of science and antithetical to scientific cultural norms and values (Harsh et al., 2011; Laursen et al., 2010). A recent qualitative study documented several defining aspects of undergraduate research experiences (Laursen et al., 2010). According to the study, authentic undergraduate research experiences typically involve working on a problem within an unknown solution (i.e., neither the undergraduate researcher nor the senior faculty investigator knows the answer). The research process involves defining methodological and intellectual obstacles, designing experiments to solve the problem, and enduring experimental failures in order to eventually come to a replicable method of solving the 
research problem (Laursen et al., 2010). In short, waning performance-avoidance goals are part of becoming a scientist, either by learning to or by being temperamentally predisposed to eschew performance-avoidance goals (Harsh et al., 2011; Laursen et al., 2010; Lopatto, 2007). Students engaged in research may be more likely to deem-phasize performanceavoidance goals in order to persist.

Research experiences also initially exhibited a positive effect on growth in task goals; however, the positive effect was suppressed with inclusion of growth in science identity. This finding was not altogether surprising, because research experience has a multitude of positive effects on psychological processes associated with socialization into the sciences. For example, undergraduate engagement in research has been shown to increase selfefficacy to do science, increase scientific identity, and provide a context wherein junior scientists are socialized into the scientific professorate (Eccles, 2009; Estrada et al., 2011; Laursen et al., 2010). Therefore, research experiences may work indirectly through gains in scientific identity to increase task goals.

In the current study, growth in scientific self-identity exhibited a strong influence on growth in task and performance-approach goals. Gains in scientific identity indicated that "being a scientist" was an increasingly central aspect of the student's self-identity. We had expected to find a positive effect of scientific identity on task goals, which implies that seeing oneself as a scientist would dispose students toward focusing on skill development; however, we were surprised to find that seeing oneself as a scientist also disposed students toward competing against and demonstrating their ability relative to peers. Upon further consideration, this finding was consistent with the process of pursuing a scientific research career, as students must develop mastery in their discipline and also be successful in the highly competitive process of gaining employment as a scientist or gaining entry into graduate school (Barron \& Harackiewicz, 2001a).

The identity-goals link was also particularly interesting in that it indicates that domain identity, in this case science self-identity, was a key factor in attaining optimal motivation. The relationship between identity and goals is an area receiving increased attention in the literature (Kaplan \& Flum, 2009). Our formulation of the process assumed that identity influenced the goals students choose to adopt; however, other theoretical models specify reciprocal relations between relevant identities and self-schema such as achievement goals (Eccles, 2009). Future research investigating the dynamics between goals and identities will certainly be needed.

\section{Influence of Goals on Distal Outcomes}

Findings from our study also showed that task and performance-avoidance goals uniquely influenced academic performance and persistence in STEM. First, the finding that task goals uniquely influence cumulative undergraduate GPA, over and above baseline GPA, is consistent with prior research. For example, prior research has shown task goals were predictive of academic performance for African American and Latino youth (Friedel et al., 2010; Gutman, 2006; Long, Monoi, Harper, Knoblauch, \& Murphy, 2007; Stevens et al., 2007). Furthermore, these findings are consistent with prior research linking task goals with academic performance among White college students in the physical sciences (Grant \& Dweck, 2003). These findings build on prior research that demonstrated that task goals are necessary for success in the sciences, perhaps due to deeper processing and associated study strategies (Grant \& Dweck, 2003; Zusho et al., 2003). However, such claims are difficult to substantiate, particularly in the context of the current study where achievement goals were in reference to school in general rather than to a specific science class. Finally, because the PALS survey items tap both normative and appearance aspects of performance-approach 
goals, it was not surprising to find that performance-approach scores were not predictive of academic success (Hulleman et al., 2010).

A second and perhaps more important finding was the unique link between performanceavoidance goals and persistence in STEM. Our models indicated that in our sample of highachieving African American and Latino students majoring in STEM disciplines, only performance-avoidance goals predicted student attrition from their original STEM major and attrition from any STEM major. This finding was consistent with research on interventions to broadening participation in STEM and research focused on the impact of undergraduate research experiences (Harsh et al., 2011; Laursen et al., 2010; Lopatto, 2007). As described above, performance-avoidance goals are not congruent with cultural norms and values within the scientific community or the daily practice of science. Therefore, individuals holding higher performance-avoidance goals were more likely to leave their original STEM major and more likely to leave STEM in general.

This finding also provides a useful contrast with other longitudinal evidence showing a relationship among task goals, interest, and field choice in samples of primarily White college students (Harackiewicz, Barron, Tauer, \& Elliot, 2002). In the prior study, researchers followed first-year students from their initial experiences in psychology, through the eventual selection of psychology as a major, and through graduation. The study focused on the choice to pursue a STEM major (i.e., psychology). By contrast, the current study focused on a sample that had already chosen a STEM major and expressed interest in a scientific research career. The only choice left to these students was to leave their original major and/or any STEM field. The decision to leave STEM may be defined as an avoidance choice rather than an approach choice. Thus, all decisions and behaviors may not be the same or be motivated by the same goal orientations. It may be useful to distinguish between avoidance behaviors and approach behaviors, which may be governed by congruent avoidance or approach motivations. The distinction between approach and avoidance behaviors and the antecedent motivations that give rise to them requires further study. Thus, the motivation to adopt a career path and the motivation to maintain it may differ.

\section{Implications}

The current study was uniquely situated at the intersection of interventions that broaden participation in STEM, such as minority training programs, and the goal theory literatures. Our findings indicate that achievement goals are an important part of the process linking interventions to key outcomes such as academic performance and persistence in STEM. The implications of this research suggest recommendations for increasing the STEM pipeline in general, as well as broadening participation in STEM.

First, the literature on research experiences for undergraduates and broadening participation in STEM has shown that research experiences tend to sustain or boost student commitment to a career in STEM across a variety of contexts (Maton \& Hrabowski, 2004; Maton et al., 2009; Russell et al., 2007; Schultz et al., 2011). Further, research with undergraduates indicates that more is better (Harsh et al., 2011; Laursen et al., 2010; Lopatto, 2007; Russell, Hancock, \& McCullough, 2006). Students experience different benefits at developmentally different stages of their academic careers. For example, early benefits of research experiences center on growth in confidence, self-efficacy, and lab skills; later benefits include learning to "think like a scientist"; ultimately, students "become a scientist" (Estrada et al., 2011; Laursen et al., 2010). Consequently, there have been increasing calls to expand access to research experiences, both earlier in college (i.e., first-year students) and at younger ages (i.e., K-12; Russell et al., 2006). However, in light of the current findings and similar studies that identify the importance of mediating beliefs, expanding early access to STEM does not give the full picture of why research experiences work. For example, adding 
a lab component to a unit in a middle school science class may not be sufficient to produce all of the desirable effects shown in the research experiences literature. The structure of the research experience should be aligned with the authentic scientific process: defining a problem with an unknown solution, identifying obstacles, attempting experimental solutions, and persisting through experimental failures until arriving at a replicable solution (Laursen et al., 2010). In other words, students may not attain the full benefits of engagement in the scientific process unless the activity involves working through setbacks and failures, which reinforce the incompatibility of the scientific process and performance-avoidance goals.

Furthermore, expanding early access to research activities could be particularly helpful for recruiting a larger proportion of under-represented students into STEM (Laursen et al., 2010; Russell et al., 2006). Research indicates that minority students often have less exposure to STEM career options. Therefore, expanded access to research activities, particularly those activities that minimize the relevance of performance-avoidance goals, may increase the proportion of underrepresented student interested in STEM disciplines at the college level (Russell et al., 2006).

In addition to calls for expanding research opportunities for younger students, there have been calls to provide guidance to and training for faculty mentors working with undergraduate mentees (Russell et al., 2006). If implemented, these guides should consider making the often tacit cultural norms and values of the scientific community explicit, most particularly the norm of resilience to failure. Mentors can be particularly helpful guiding mentees to think through and discuss the intellectual and emotional process of pursuing research problems (Russell et al., 2006). The reflection process may help students gain insights into their own growth as scientists and bring about awareness of how they deal with struggles and frustrations (Laursen et al., 2010). Guided discussions may help mentees identify and replace their own motivation to avoid failure with more adaptive intellectual and emotional processes for dealing with struggles and frustrations. This process may be particularly helpful for students from minority groups that face additional challenges related to stereotype threat. Recent research has indicated that stereotype threat works in part by engendering performance-avoidance goals (Brodish \& Devine, 2009; Smith, 2004, 2006). Faculty mentors may be able to help mentees decouple the experience of an experimental failure with threats to their ability to conduct science or belong in scientific community.

Finally, as implied in the opening vignette describing Mark, Sam, and Esmeralda (Barron \& Harackiewicz, 2001a), there are often limitations to individual faculty members' capacity to include undergraduates in their lab research or limited resources for other types of undergraduate research experiences (Laursen et al., 2010). Faculty or program staff often select who should be granted access into their labs based on academic preparation (i.e., grades or GPA) and interpersonal fit (Laursen et al., 2010); however, other factors often play an important role in the recruitment and retention of talented students in STEM disciplines (Laursen et al., 2010). For example, the theme of resilience to failure emerged from interviews with faculty mentors. These science faculty reported having high expectations for high-achieving students in their labs, only to see these students quit due to an inability to cope with frustrations in the practice of science. However, they also reported identifying less academically prepared "diamonds in the rough" who had the temperament to succeed in science (Laursen et al., 2010). The implication is that faculty and program staff should consider reaching out to a broader range of students and expanding their selection criteria to include factors related to resilience such as low performance-avoidance goals.

\section{Caveats}

Our findings indicate that goal theory can help our understanding of the "leaky" STEM pipeline problem; however, there were a number of limitations to the current study that 
should caution the reader against overgeneralization. The first limitation of the study concerns characteristics of the sample. The current study (i.e., TheScienceStudy) purposefully recruited a sample of high-achieving, underrepresented minority students, many of whom were enrolled in training programs aimed at broadening participation in STEM. Therefore, the current sample may think and behave in ways that are more similar to high-achieving majority students than to low-achieving minority students.

A related caveat is that we did not include majority White and Asian students in the current study. The absence of majority group members limits cross-group comparisons in the STEM context. Future research should include both majority and minority groups in STEM to allow for a full empirical comparison of the similarities and differences across groups. Although both groups benefit from hands-on research (Laursen et al., 2010), our findings indicate that the negative relationship between performance-avoidance goals and achievement is particularly strong in minority groups. Future research should assess if these research experiences uniquely buffer minority students from the detrimental effects of stereotype threat. This would require researchers to assess how the climate inside and outside STEM classrooms influences stereotype threat, which would allow for the assessment of how stereotype threat is acting on the activation of performance-avoidance goals.

A further limitation of the current study concerned the level of specificity of our measure of achievement goals. This study measured goal orientations at a higher level of abstraction than prior investigations among college students. As described above, the PALS goal orientation scales measure goals toward "school" rather than goal orientations science, or STEM, or a specific STEM class. Because the reference for our measure was school rather than STEM, we interpret their goals as global dispositions toward school, which may limit generalizations to goals within any particular classroom or toward STEM.

A final caveat was the nature of the research and mentoring measurements. These measurements did not discriminate between the various types of activities in which students engaged, nor did they measure the quality of the mentor-mentee relationship. Future research should assess the impact of specific types of research experiences on goal orientations to determine if there are optimal types of research involvement that are most beneficial to student goals. In addition, tracking the quality of the mentoring relationship as a potential moderator of the effect of mentoring on student goal orientations would extend the current research in potentially fruitful directions.

\section{Conclusion}

Our purpose in this study was to examine the "leaky" STEM pipeline problem from a goal theory perspective and thereby bridge the gap between these two literatures. As we had suspected, interventions to broaden participation work in part because students align their goals with the norms, values, and contextual demands in STEM fields. Research experiences and growth in scientific self-identity appear to align student goal orientations toward optimal motivation (increasing task and performance-approach goals) while they buffer students from maladaptive trends in performance-avoidance goals. Further, task goals uniquely influenced academic success, and higher performance-avoidance goals led to lower rates of persistence in STEM.

\section{Supplementary Material}

Refer to Web version on PubMed Central for supplementary material. 


\section{Acknowledgments}

The research reported in this article was supported by a grant from the National Institutes of Health (R01GM075316). We gratefully acknowledge Karen E. Rambo-Hernandez and H. Jane Rogers for their helpful comments and suggestions regarding this article. We gratefully acknowledge Maria Aguilar's contributions to this research.

\section{Appendix: Item Contents}

The next set of questions also relate to your feelings about yourself as a student. Please select the best answer on the scale from 1 (strongly disagree) to 5 (strongly agree).

*TGO-1. I like school work that I'll learn from, even if I make a lot of mistakes.

*TGO-2. An important reason why I do my school work is because I like to learn new things.

*TGO-3. I like school work best when it really makes me think.

*TGO-4. An important reason why I do my work in school is because I want to get better at it.

*TGO-5. I do my school work because I'm interested in it.

*TGO-6. An important reason I do my school work is because I enjoy it.

*PAp-1. I would feel really good if I were the only one who could answer the teacher's questions in class.

*PAp-2. It's important to me that the other students in my classes think that I am good at my work.

*PAp-3. I want to do better than other students in my classes.

*PAp-4. I would feel successful in school if I did better than most of the other students.

*PAp-5. I would like to show my teachers that I'm smarter than the other students in my classes.

*PAp-6. Doing better than other students in school is important to me.

*PAv-1. It's very important to me that I don't look stupid in my classes.

*PAv-2. An important reason I do my school work is so that I don't embarrass myself.

*PAv-3. The reason I do my school work is so my teachers don't think I know less than others.

*PAv-4. The reason I do my school work is so others won't think I'm dumb.

*PAv-5. One reason I would not participate in class is to avoid looking stupid.

*PAv-6. One of my main goals is to avoid looking like I can't do my work.

Note. An asterisk indicates an item included in modified (shortened) version of the PALS. From "The Development and Validation of Scales Assessing Students' Achievement Goal Orientations," by C. Midgley, A. Kaplan, M. Middleton, M. L. Maehr, T. Urdan, L. H. 
Anderman, E. Anderman, \& R. Roeser, 1998, Contemporary Educational Psychology, 23, pp. 113-131. Copyright 1998 by Elsevier. Reprinted with permission.

\section{References}

Alper J. The pipeline is leaking women all the way along. Science. 1993 Apr 16.260:409-411.10.1126/ science.260.5106.409 [PubMed: 17838262]

Ames C. Classrooms: Goals, structures, and student motivation. Journal of Educational Psychology. 1992; 84:261-271.10.1037/0022-0663.84.3.261

Ames C, Archer J. Mothers' beliefs about the role of ability and effort in school learning. Journal of Educational Psychology. 1987; 79:409-414.10.1037/0022-0663.79.4.409

Ames C, Archer J. Achievement goals in the classroom: Students' learning strategies and motivation processes. Journal of Educational Psychology. 1988; 80:260-267.10.1037/0022-0663.80.3.260

Anderman EM, Maehr ML. Motivation and schooling in the middle grades. Review of Educational Research. 1994; 64:287-309.10.3102/00346543064002287

Anderman EM, Midgley C. Changes in achievement goal orientations, perceived academic competence, and grades across the transition to middle-level schools. Contemporary Educational Psychology. 1997; 22:269-298.10.1006/ceps.1996.0926 [PubMed: 9237829]

Anderman EM, Young AJ. Motivation and strategy use in science: Individual differences and classroom effects. Journal of Research in Science Teaching. 1994; 31:811-831.10.1002/tea. 3660310805

Anderman LH, Anderman EM. Social predictors of changes in students' achievement goal orientations. Contemporary Educational Psychology. 1999; 24:21-37.10.1006/ceps.1998.0978 [PubMed: 9878206]

Atkinson JW. Motivational determinants of risk-taking behavior. Psychological Review. 1957; 64:359-372.10.1037/h0043445 [PubMed: 13505972]

Bandura, A. Social foundations of thought and action: A social cognitive theory. Englewood Cliffs, NJ: Prentice-Hall; 1986.

Barron, KE.; Harackiewicz, JM. Achievement goals and optimal motivation: A multiple goals perspective. In: Sansone, C.; Harackiewicz, JM., editors. Intrinsic and extrinsic motivation: The search for optimal motivation and performance. San Diego, CA: Academic Press; 2001a. p. 231-256.

Barron KE, Harackiewicz JM. Achievement goals and optimal motivation: Testing multiple goal models. Journal of Personality and Social Psychology. 2001b; 80:706722.10.1037/0022-3514.80.5.706 [PubMed: 11374744]

Battle A, Wigfield A. College women's value orientations toward family, career, and graduate school. Journal of Vocational Behavior. 2003; 62:56-75.10.1016/S0001-8791(02)00037-4

Berryman, SE. Who will do science? Trends, and their causes in minority and female representation among holders of advanced degrees in science and mathematics: A special report. New York, NY: Rockefeller Foundation; 1983.

Brodish AB, Devine PG. The role of performance-avoidance goals and worry in mediating the relationship between stereotype threat and performance. Journal of Experimental Social Psychology. 2009; 45:180-185.10.1016/j.jesp.2008.08.005

Brown, TA. CFA with equality constraints, multiple groups, and mean structures. In: Kenny, DA., editor. Confirmatory factor analysis for applied research. New York, NY: Guilford Press; 2006. p. 212-235.

Brown-Wright L, Tyler K. The effects of home-school dissonance on African American male high school students. Journal of Negro Education. 2010; 79:125-136.

Byars-Winston A, Estrada Y, Howard C, Davis D, Zalapa J. Influence of social cognitive and ethnic variables on academic goals of underrepresented students in science and engineering: A multiplegroups analysis. Journal of Counseling Psychology. 2010; 57:205-218.10.1037/a0018608 [PubMed: 20495610] 
Carter FD, Mandell MB, Maton KI. The influence of on-campus, academic year undergraduate research on STEM Ph. D. outcomes: Evidence from the Meyerhoff scholarship program. Educational Evaluation and Policy Analysis. 2009; 31:441-462. [PubMed: 21785521]

Chemers, MM.; Syed, M.; Goza, BK.; Zurbriggen, EL.; Bearman, S.; Crosby, FJ.; Morgan, FJ. The role of self-efficacy and identity in mediating the effects of science support programs (Technical Report No 5). Santa Cruz: University of California; 2010.

Collea FP. Increasing minorities in science and engineering. A critical look at two programs. Journal of College Science Teaching. 1990; 20:31-34.

Cook, BJ.; Córdova, DI. Minorities in higher education twenty-second annual status report: 2007 supplement. Washington, DC: American Council on Education; 2007.

Covington MV. Goal theory, motivation, and school achievement: An integrative review. Annual Review of Psychology. 2000; 51:171-200.10.1146/annurev.psych.51.1.171

Denofrio LA, Russell B, Lopatto D, Lu Y. Linking student interests to science curricula. Science. 2007 Dec 21.318:1872-1873.10.1126/science.1150788 [PubMed: 18096791]

Duchesne S, Ratelle C. Parental behaviors and adolescents' achievement goals at the beginning of middle school: Emotional problems as potential mediators. Journal of Educational Psychology. 2010; 102:497-507.10.1037/a0019320

Dweck CS. Motivational processes affecting learning. American Psychologist. 1986; 41:10401048.10.1037/0003-066X.41.10.1040

Dweck CS, Chiu C, Hong Y. Implicit theories: Elaboration and extension of the model. Psychological Inquiry. 1995a; 6:322-333.10.1207/s15327965pli0604_12

Dweck CS, Chiu C, Hong Y. Implicit theories and their role in judgments and reactions: A world from two perspectives. Psychological Inquiry. 1995b; 6:267-285.10.1207/s15327965pli0604_1

Dweck CS, Leggett EL. A social-cognitive approach to motivation and personality. Psychological Review. 1988; 95:256-273.10.1037/0033-295X.95.2.256

Eccles JS. Understanding women's educational and occupational choices: Applying the Eccles et al model of achievement-related choices. Psychology of Women Quarterly. 1994; 18:585609.10.1111/j.1471-6402.1994.tb01049.x

Eccles J. Who am I and what am I going to do with my life? Personal and collective identities as motivators of action. Educational Psychologist. 2009; 44:78-89.10.1080/00461520902832368

Eccles, JS.; Adler, TF.; Futterman, R.; Goff, SB.; Kaczala, CM.; Meece, JL.; Midgley, C. Expectancies, values, and academic behaviors. In: Spence, JT., editor. Achievement and achievement motivation. San Francisco, CA: Freeman; 1983. p. 75-146.

Eccles (Parsons) JE, Adler T, Meece JL. Sex differences in achievement: A test of alternate theories. Journal of Personality and Social Psychology. 1984; 46:26-43.10.1037/0022-3514.46.1.26

Eccles JS, Wigfield A, Flanagan CA, Mller C. Selfconcepts, domain values, and self-esteem: Relations and changes at early adolescence. Journal of Personality. 1989; 57:283-310.10.1111/j. 1467-6494.1989.tb00484.x [PubMed: 2769558]

Egan TM. The impact of learning goal orientation similarity on formal mentoring relationship outcomes. Advances in Developing Human Resources. 2005; 7:489_ 504.10.1177/1523422305279679

Elliot AJ, Church MA. A hierarchical model of approach and avoidance achievement motivation. Journal of Personality and Social Psychology. 1997; 72:218-232.10.1037/0022-3514.72.1.218

Elliot AJ, Harackiewicz JM. Approach and avoidance achievement goal orientations and intrinsic motivation: A mediational analysis. Journal of Personality and Social Psychology. 1996; 70:461475.10.1037/0022-3514.70.3.461

Elliot AJ, McGregor HA. A $2 \times 2$ achievement goal framework. Journal of Personality and Social Psychology. 2001; 80:501-519.10.1037/0022-3514.80.3.501 [PubMed: 11300582]

Elliott ES, Dweck CS. Goals: An approach to motivation and achievement. Journal of Personality and Social Psychology. 1988; 54:5-12.10.1037/0022-3514.54.1.5 [PubMed: 3346808]

Estrada M, Woodcock A, Hernandez PR, Schultz PW. Toward a model of social influence that explains minority student integration into the scientific community. Journal of Educational Psychology. 2011; 103:206-222.10.1037/a0020743 [PubMed: 21552374] 
Fechheimer M, Webber K, Kleiber PB. How well do undergraduate research programs promote engagement and success of students? CBE Life Sciences Education. 2011; 10:156-163.10.1187/ cbe.10-10-0130 [PubMed: 21633064]

Friedel JM, Cortina KS, Turner JC, Midgley C. Changes in efficacy beliefs in mathematics across the transition to middle school: Examining the effects of perceived teacher and parent goal emphases. Journal of Educational Psychology. 2010; 102:102-114.10.1037/a0017590

Fryer JW, Elliot AJ. Stability and change in achievement goals. Journal of Educational Psychology. 2007; 99:700-714.10.1037/0022-0663.99.4.700

Godshalk VM, Sosik JJ. Aiming for career success: The role of learning goal orientation in mentoring relationships. Journal of Vocational Behavior. 2003; 63:417-437.10.1016/S0001-8791(02)00038-6

Gonida EN, Voulala K, Kiosseoglou G. Students' achievement goal orientations and their behavioral and emotional engagement: Co-examining the role of perceived school goal structures and parent goals during adolescence. Learning and Individual Differences. 2009; 19:53-60.10.1016/j.lindif. 2008.04.002

Grant H, Dweck CS. Clarifying achievement goals and their impact. Journal of Personality and Social Psychology. 2003; 85:541-553.10.1037/0022-3514.85.3.541 [PubMed: 14498789]

Gutman LM. How student and parent goal orientations and classroom goal structures influence the math achievement of African Americans during the high school transition. Contemporary Educational Psychology. 2006; 31:44-63.10.1016/j.cedpsych.2005.01.004

Harackiewicz JM, Barron KE, Carter SM, Lehto AT, Elliot AJ. Predictors and consequences of achievement goals in the college classroom: Maintaining interest and making the grade. Journal of Personality and Social Psychology. 1997; 73:1284-1295.10.1037/0022-3514.73.6.1284

Harackiewicz JM, Barron KE, Elliot AJ. Rethinking achievement goals: When are they adaptive for college students and why? Educational Psychologist. 1998; 33:1-21.10.1207/s15326985ep3301_1

Harackiewicz JM, Barron KE, Pintrich PR, Elliot AJ, Thrash TM. Revision of achievement goal theory: Necessary and illuminating. Journal of Educational Psychology. 2002; 94:638645.10.1037/0022-0663.94.3.638

Harackiewicz JM, Barron KE, Tauer JM, Carter SM, Elliot AJ. Short-term and long-term consequences of achievement goals: Predicting interest and performance over time. Journal of Educational Psychology. 2000; 92:316-330.10.1037/0022-0663.92.2.316

Harackiewicz JM, Barron KE, Tauer JM, Elliot AJ. Predicting success in college: A longitudinal study of achievement goals and ability measures as predictors of interest and performance from freshman year through graduation. Journal of Educational Psychology. 2002; 94:562575.10.1037/0022-0663.94.3.562

Harackiewicz JM, Elliot AJ. The joint effects of target and purpose goals on intrinsic motivation: A mediational analysis. Personality and Social Psychology Bulletin. 1998; 24:675689.10.1177/0146167298247001

Haring MJ. The case for a conceptual base for minority mentoring programs. Peabody Journal of Education. 1999; 74:5-14.10.1207/s15327930pje7402_2

Harsh JA, Maltese AV, Tai RH. Undergraduate research experiences from a longitudinal perspective. Journal of College Science Teaching. 2011; 41:84-91.

Hox, J. Multilevel analysis: Techniques and applications. Mahwah, NJ: Erlbaum; 2002.

$\mathrm{Hu}$ L, Bentler PM. Fit indices in covariance structure modeling: Sensitivity to underparameterized model specification. Psychological Methods. 1998; 3:424-453.10.1037/1082-989X.3.4.424

Hui CH, Triandis HC. Measurement in cross-cultural psychology: A review and comparison of strategies. Journal of Cross-Cultural Psychology. 1985; 16:131152.10.1177/0022002185016002001

Hulleman CS, Schrager SM, Bodmann SM, Harackiewicz JM. A meta-analytic review of achievement goal measures: Different labels for the same constructs or different constructs with similar labels? Psychological Bulletin. 2010; 136:422-449.10.1037/a0018947 [PubMed: 20438145]

Hurtado S, Cabrera NL, Lin MH, Arellano L, Espinosa LL. Diversifying science: Underrepresented student experiences in structured research programs. Research in Higher Education. 2009; 50:189214.10.1007/s11162-008-9114-7 [PubMed: 23503690] 
Jacobs JE. Twenty-five years of research on gender and ethnic differences in math and science career choices: What have we learned? New Directions for Child and Adolescent Development. 2005; 2005:85-94.10.1002/cd.151 [PubMed: 16509541]

Jacobs, JE.; Eccles, JS. Parents, task values, and real-life achievement-related choices. In: Sansone, C.; Harackiewicz, JM., editors. Intrinsic and extrinsic motivation: The search for optimal motivation and performance. San Diego, CA: Academic Press; 2000. p. 405-439.

Kaplan A, Flum H. Motivation and identity: The relations of action and development in educational contexts-An introduction to the special issue. Educational Psychologist. 2009; 44:7377.10.1080/00461520902832418

Kaplan A, Maehr ML. The contributions and prospects of goal orientation theory. Educational Psychology Review. 2007; 19:141-184.10.1007/s10648-006-9012-5

Kardash CAM. Evaluation of undergraduate research experience: Perceptions of undergraduate interns and their faculty mentors. Journal of Educational Psychology. 2000; 92:191201.10.1037/0022-0663.92.1.191

Kline, RB. Principles and practice of structural equation modeling. 2nd. New York, NY: Guilford Press; 2005.

Koenig R. Minority retention rates in science are a sore spot for most universities. Science. 2009 Jun 12.324:1386-1387.10.1126/science.324_1386a

Laursen, S.; Hunter, A.; Seymour, E.; Thiry, H.; Melton, G. Undergraduate research in the sciences: Engaging students in real science. San Francisco, CA: Wiley; 2010.

Lent RW, Brown SD. Social cognitive approach to career development: An overview. Career Development Quarterly. 1996; 44:310-321.10.1002/j.2161-0045.1996.tb00448.x

Lent RW, Lopez FG, Sheu HB, Lopez AM. Social cognitive predictors of the interests and choices of computing majors: Applicability to underrepresented students. Journal of Vocational Behavior. 2011; 78:184-192.10.1016/j.jvb.2010.10.006

Lockwood P, Jordan CH, Kunda Z. Motivation by positive or negative role models: Regulatory focus determines who will best inspire us. Journal of Personality and Social Psychology. 2002; 83:854864.10.1037/0022-3514.83.4.854 [PubMed: 12374440]

Long JF, Monoi S, Harper B, Knoblauch D, Murphy PK. Academic motivation and achievement among urban adolescents. Urban Education. 2007; 42:196-222.10.1177/0042085907300447

Lopatto D. Undergraduate research experiences support science career decisions and active learning. CBE Life Sciences Education. 2007; 6:297-306.10.1187/cbe.07-06-0039 [PubMed: 18056301]

Maehr ML. The "psychological environment" of the school: A focus for school leadership. Advances in Educational Administration. 1991; 2:51-81.

Maehr ML, Meyer HA. Understanding motivation and schooling: Where we've been, where we are, where we need to go. Educational Psychology Review. 1997; 9:371-409.10.1023/A: 1024750807365

Maton KI, Hrabowski FA. Increasing the number of African American PhDs in the sciences and engineering: A strengths-based approach. American Psychologist. 2004; 59:547556.10.1037/0003-066X.59.6.547 [PubMed: 15367090]

Maton KI, Sto Domingo MR, Stolle-McAllister KE, Zimmerman JL, Hrabowski FA III. Enhancing the number of African-Americans who pursue STEM PhDs: Meyerhoff scholarship program outcomes, processes, and individual predictors. Journal of Women and Minorities in Science and Engineering. 2009; 15:15-37.10.1615/JWomenMinorScienEng.v15.i1.20 [PubMed: 21841904]

McCaslin M. Co-regulation of student motivation and emergent identity. Educational Psychologist. 2009; 44:137-146.10.1080/00461520902832384

McCoach DB, Kaniskan B. Using time-varying covariates in multilevel growth models. Frontiers in Quantitative Psychology and Measurement. 2010; 1 Article 17. 10.3389/fpsyg.2010.00017

Meece JL, Miller SD. A longitudinal analysis of elementary school students' achievement goals in literacy activities. Contemporary Educational Psychology. 2001; 26:454-480.10.1006/ceps. 2000.1071 [PubMed: 11681828]

Middleton MJ, Kaplan A, Midgley C. The change in middle school students' achievement goals in mathematics over time. Social Psychology of Education. 2004; 7:289-311.10.1023/B:SPOE. 0000037484.86850.fa 
Midgley C, Kaplan A, Middleton M, Maehr ML, Urdan T, Anderman LH, et al. Roeser R. The development and validation of scales assessing students' achievement goal orientations. Contemporary Educational Psychology. 1998; 23:113-131.10.1006/ceps.1998.0965 [PubMed: 9576837]

Muthén, LK.; Muthén, BO. MPlus user's guide. 5th. Los Angeles, CA: Author; 1998-2009.

Myers CB, Pavel DM. Underrepresented students in STEM: The transition from undergraduate to graduate programs. Journal of Diversity in Higher Education. 2011; 4:90-105.10.1037/a0021679

Nicholls JG. Achievement motivation: Conceptions of ability, subjective experience, task choice, and performance. Psychological Review. 1984; 91:328-346.10.1037/0033-295X.91.3.328

Payne SC, Youngcourt SS, Beaubien JM. A meta-analytic examination of the goal orientation nomological net. Journal of Applied Psychology. 2007; 92:128-150.10.1037/0021-9010.92.1.128 [PubMed: 17227156]

Pender M, Marcotte DE, Sto Domingo MR, Maton KI. The STEM pipeline: The role of summer research experience in minority students' Ph.D. aspirations. Education Policy Analysis Archives. 2010; 18:1-36. [PubMed: 21841903]

Pfund C, Pribbenow CM, Branchaw J, Lauffer SM, Handelsman J. The merits of training mentors. Science. 2006 Jan 27.311:473-474.10.1126/science.1123806 [PubMed: 16439648]

Pintrich PR. The role of motivation in promoting and sustaining self-regulated learning. International Journal of Educational Research. 1999; 31:459-470.10.1016/S0883-0355(99)00015-4

Pintrich PR. An achievement goal theory perspective on issues in motivation terminology, theory, and research. Contemporary Educational Psychology. 2000; 25:92-104.10.1006/ceps.1999.1017 [PubMed: 10620384]

Pintrich PR, de Groot EV. Motivational and self-regulated learning components of classroom academic performance. Journal of Educational Psychology. 1990; 82:3340.10.1037/0022-0663.82.1.33

Pintrich, PR.; Schunk, DH. Motivation in education: Theory, research, and applications. Englewood Cliffs, NJ: Prentice-Hall; 2002a.

Pintrich, PR.; Schunk, DH. The role of goals and goal orientations. In: Davis, KM., editor. Motivation in education: Theory, research, and applications. Englewood Cliffs, NJ: Prentice-Hall; 2002b. p. 199-254.

Raudenbush, SW.; Bryk, AS. Hierarchical linear models: Applications and data analysis methods. 2nd. Newbury Park, CA: Sage; 2002.

Roeser, R.; Lau, S. On academic identity formation in middle school settings during early adolescence: A motivational-contextual perspective. In: Brinthaupt, TM.; Lipka, RP., editors. Understanding early adolescence self and identity: Applications and interventions. Albany: State University of New York Press; 2002. p. 91-131.

Ross ME, Blackburn M, Forbes S. Reliability generalization of the patterns of adaptive learning survey goal orientation scales. Educational and Psychological Measurement. 2005; 65:451464.10.1177/0013164404272496

Ross ME, Shannon DM, Salisbury-Glennon JD, Guarino A. The Patterns of Adaptive Learning Survey: A comparison across grade levels. Educational and Psychological Measurement. 2002; 62:483-497.10.1177/00164402062003006

Russell, SH.; Hancock, MP.; McCullough, J. Evaluation of NSF support for undergraduate research opportunities: Synthesis report. Arlington, VA: National Science Foundation; 2006. p. 1-28.

Russell SH, Hancock MP, McCullough J. Benefits of undergraduate research experiences. Science. 2007 Apr 27.316:548-549.10.1126/science.1140384 [PubMed: 17463273]

Schultz PW, Hernandez PR, Woodcock A, Estrada M, Chance RC, Aguilar M, Serpe RT. Patching the pipeline: Reducing educational disparities in the sciences through minority training programs. Educational Evaluation and Policy Analysis. 2011; 33:95-114.10.3102/0162373710392371

Schunk DH. Modeling and attributional effects on children's achievement: A self-efficacy analysis. Journal of Educational Psychology. 1981; 73:93-105.10.1037/0022-0663.73.1.93

Schunk DH. Effects of effort attributional feedback on children's perceived self-efficacy and achievement. Journal of Educational Psychology. 1982; 74:548556.10.1037/0022-0663.74.4.548 
Schunk DH. Self-efficacy perspective on achievement behavior. Educational Psychologist. 1984; 19:48-58.10.1080/00461528409529281

Senko C, Harackiewicz JM. Regulation of achievement goals: The role of competence feedback. Journal of Educational Psychology. 2005; 97:320-336.10.1037/0022-0663.97.3.320

Shah, JY.; Kruglanski, AW. The structure and substance of intrinsic motivation. In: Sansone, C.; Harackiewicz, JM., editors. Intrinsic and extrinsic motivation: The search for optimal motivation and performance. San Diego, CA: Academic Press; 2000. p. 105-127.

Shim SS, Ryan AM, Anderson CJ. Achievement goals and achievement during early adolescence: Examining time-varying predictor and outcome variables in growth-curve analysis. Journal of Educational Psychology. 2008; 100:655-671.10.1037/0022-0663.100.3.655

Smith JL. Understanding the process of stereotype threat: A review of mediational variables and new performance goal directions. Educational Psychology Review. 2004; 16:177-206.10.1023/ B:EDPR.0000034020.20317.89

Smith JL. The interplay among stereotypes, performance-avoidance goals, and women's math performance expectations. Sex Roles. 2006; 54:287-296.10.1007/s11199-006-9345-z

Smith JL, Sansone C, White PH. The stereotyped task engagement process: The role of interest and achievement motivation. Journal of Educational Psychology. 2007; 99:99_ 114.10.1037/0022-0663.99.1.99

Snyder, TD.; Hoffman, CM. Digest of education statistics 2000. Washington, DC: U.S. Department of Education, National Center for Education Statistics; 2001.

Snyder, TD.; Tan, AG. Digest of education statistics 2005. Washington, DC: U.S. Department of Education, National Center for Education Statistics; 2006.

Stevens T, Hamman D, Olivárez A Jr. Hispanic students' perception of White teachers' mastery goal orientation influences sense of school belonging. Journal of Latinos and Education. 2007; 6:5570.10.1207/s1532771xjle0601_4

Tyler K, Brown-Wright L, Stevens-Watkins D, Thomas D, Stevens R, Roan-Belle C, Smith L. Linking home-school dissonance to school-based outcomes for African American high school students. Journal of Black Psychology. 2010; 36:410-425.10.1177/0095798409353758

Villarejo M, Barlow AEL, Kogan D, Veazey BD, Sweeney JK. Encouraging minority undergraduates to choose sciencecareers: Career paths survey results. CBE-Life Sciences Education. 2008; 7:394-409.10.1187/cbe.08-04-0018 [PubMed: 19047426]

Wentzel KR. Social relationships and motivation in middle school: The role of parents, teachers, and peers. Journal of Educational Psychology. 1998; 90:202-209.10.1037/0022-0663.90.2.202

Wigfield A, Eccles J. Expectancy-value theory of achievement motivation. Contemporary Educational Psychology. 2000; 25:68-81.10.1006/ceps.1999.1015 [PubMed: 10620382]

Wigfield, A.; Wagner, AL. Competence, motivation, and identity development during adolescence. In: Elliot, AJ.; Dweck, CS., editors. Handbook of competence and motivation. NewYork, NY: Guilford Press; 2005. p. 222-239.

Wilkins NJ, Kuperminc GP. Why try? Achievementmotivation and perceived academic climate among Latino youth. Journal of Early Adolescence. 2010; 30:246-276.10.1177/0272431609333303

Wilson ZS, Holmes L, deGravelles K, Sylvain MR, Batiste L, Johnson M, Warner IM. Hierarchical mentoring: A transformative strategy for improving diversity and retention in undergraduate STEM disciplines. Journal of Science Education and Technology. 2012; 21:148-156.10.1007/ s10956-011-9292-5

Witkow MR, Fuligni AJ. Achievement goals and daily school experiences among adolescents with Asian, Latino, and European American backgrounds. Journal of Educational Psychology. 2007; 99:584-596.10.1037/0022-0663.99.3.584

Zusho A, Pintrich PR, Coppola B. Skill and will: The role of motivation and cognition in the learning of college chemistry. International Journal of Science Education. 2003; 25:10811094.10.1080/0950069032000052207

Zydney AL, Bennett JS, Shahid A, Bauer KW. Impact of undergraduate research experience in engineering. Journal of Engineering Education. 2002; 91:151-157. 


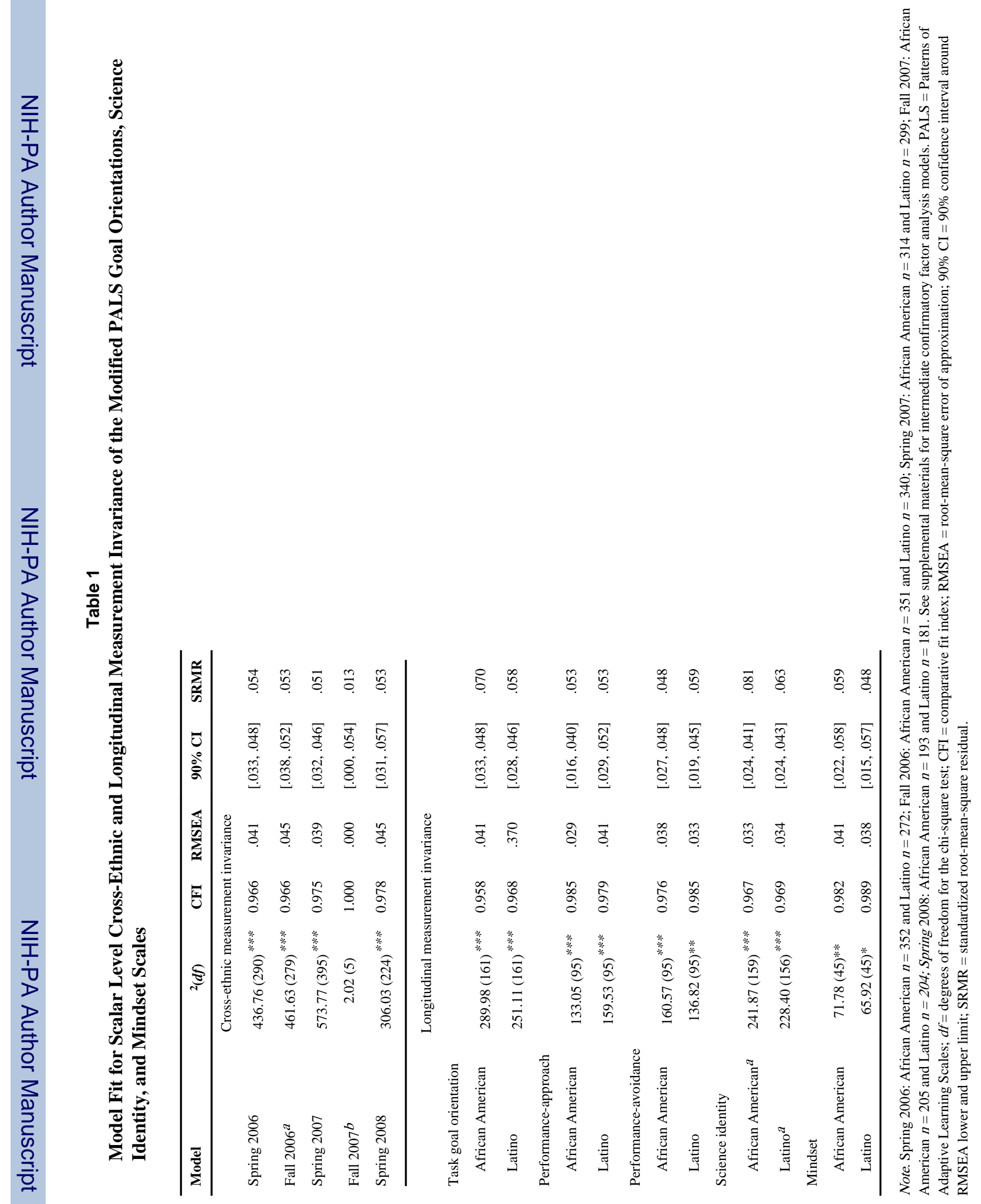




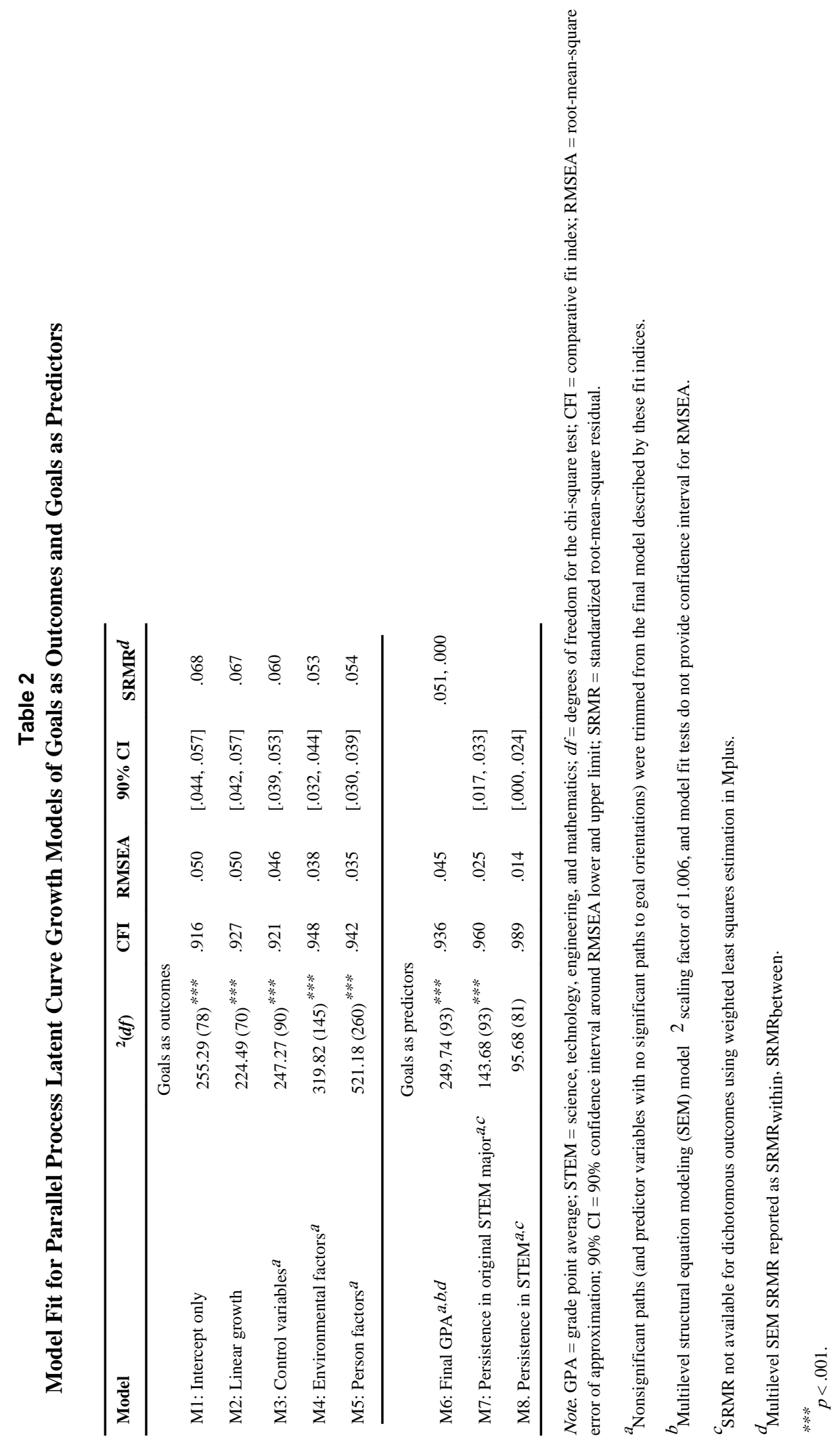




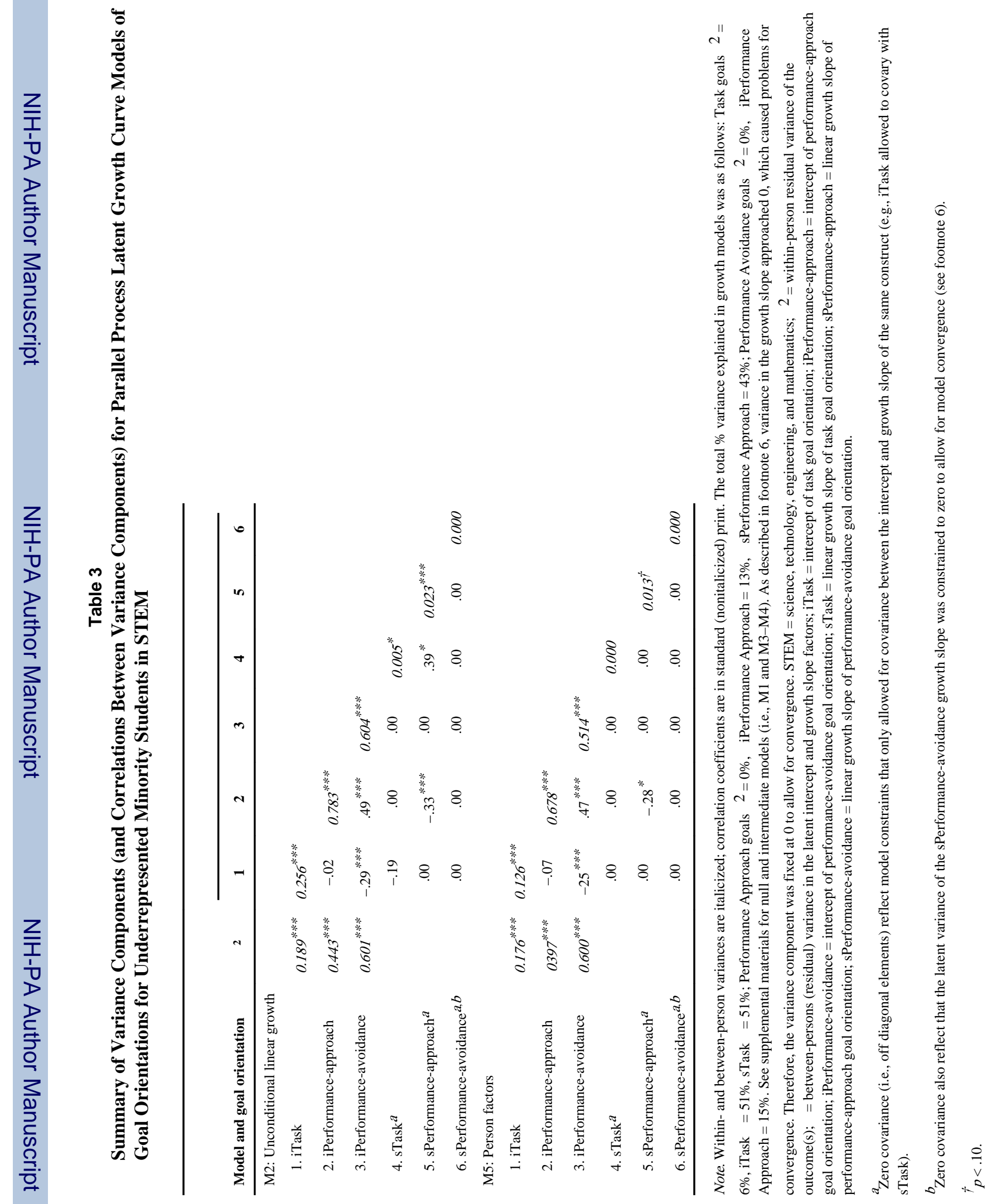


b के

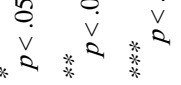$$
\text { . }
$$ 


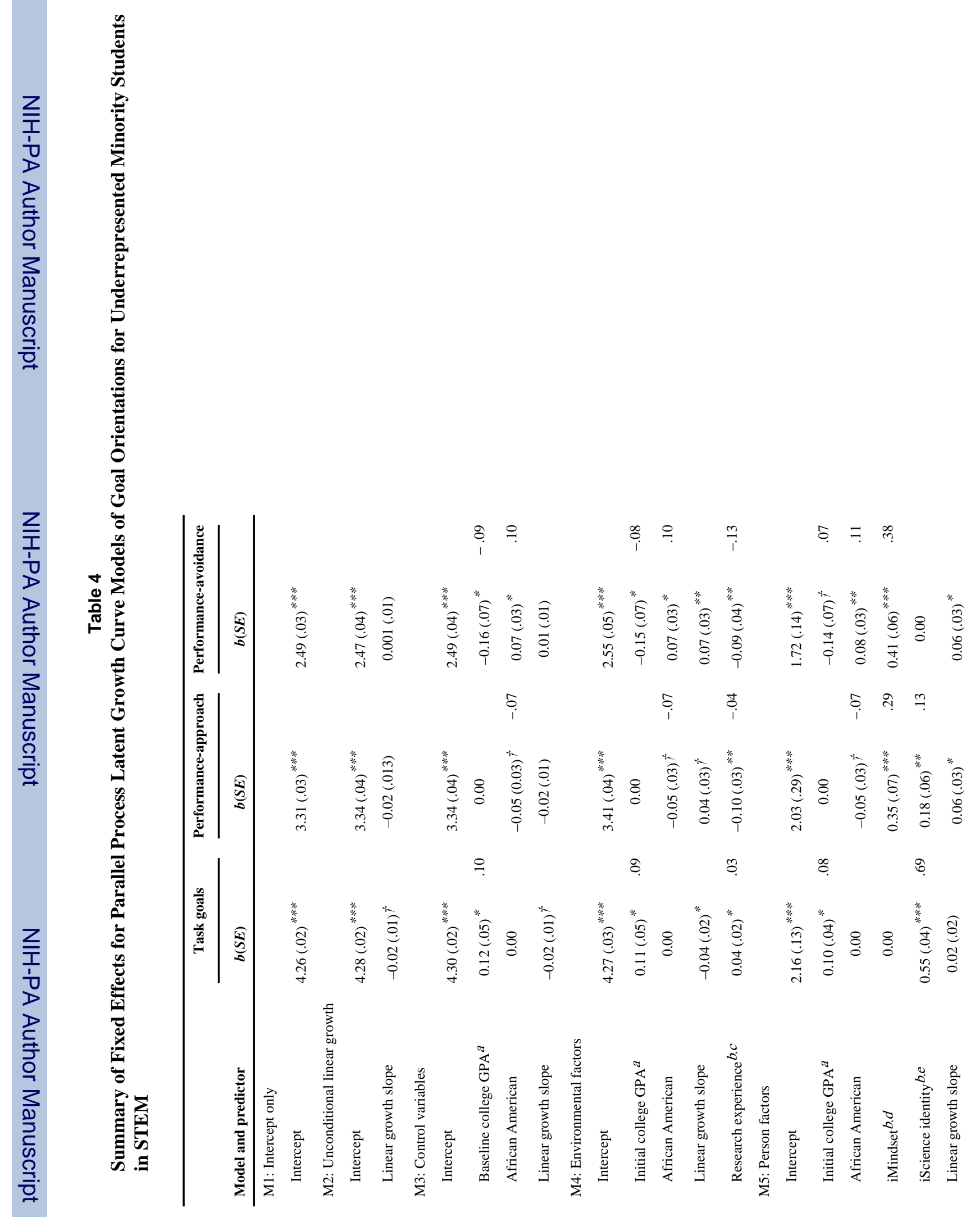


111

के

范

安

这.

要递

产磁

5n 11

흥 डे

产

눙

政

응 응

ot

跑

ज

o 5

造

政

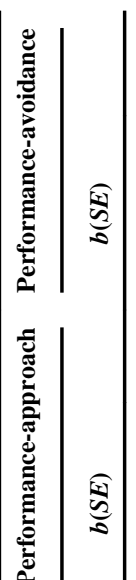

해응

son

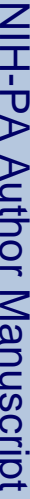

*

$\begin{array}{ll}0 . & 0 \\ 0 & 0 \\ 0 & 0\end{array}$

ज़

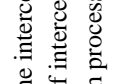

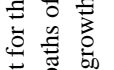

可

论

氜

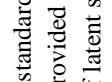

跑

II 중 훈

范

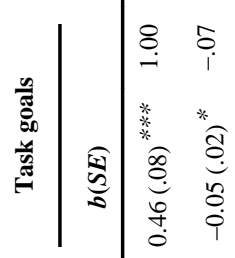

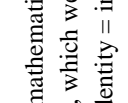

ह

कo

$\begin{array}{lll}\square & 0 & 0 \\ 0 & 0 & 0\end{array}$

$\dot{8}$

สิ่

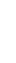

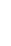

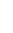

